\title{
Mimetic Herding Behavior and the Decision to Strategically Default
}

\author{
Michael J. Seiler • Mark A. Lane • \\ David M. Harrison
}

(C) Springer Science+Business Media, LLC 2012

\begin{abstract}
This study examines the herding behavior of individuals in the context of their willingness to strategically default on a mortgage based on the (falsely) observed behavior of those around them. We find that homeowners are easily persuaded to follow the herd and adopt a strategic default proclivity consistent with that of their peers. Herding behavior is stronger when a Maven, or thought leader, is involved and weaker when the person finds strategic default to be morally objectionable. Homeowners appear to herd more for informational gains rather than for social reasons, and do not herd differentially based on signal strength. In a robustness check using a sample of real estate professionals, the strong mimetic herding result continues to hold.
\end{abstract}

Keywords Mimetic herding $\cdot$ Strategic mortgage default $\cdot$ Maven $\cdot$ Signal strength

JEL Classifications $\mathrm{C} 83 \cdot \mathrm{C} 93 \cdot \mathrm{D} 19 \cdot \mathrm{G} 01 \cdot \mathrm{G} 02 \cdot \mathrm{R} 20$

M. J. Seiler $(\bowtie) \cdot$ M. A. Lane

Old Dominion University, College of Business Administration, Norfolk, VA 23529-0223, USA

e-mail: mseiler@odu.edu

M. A. Lane

e-mail: malane@odu.edu

D. M. Harrison

Rawls College of Business Administration, Texas Tech University, Lubbock, TX 79409, USA

e-mail: david.m.harrison@ttu.edu 


\section{Introduction}

Rogers (1962) describes the theory of Mimetics as a biological predisposition to learn through the emulation of observed behavior. Babies mimic the facial expressions of adults long before they understand the intricacies of the emotions those facial expressions convey. This type of social learning through imitation is one of the earliest forms of learning and never leaves us, even as adults (Marsden 1998). Since mimetic behavior is conducted on a sub-conscious level, people are unaware, and often do not believe, they can be readily influenced by simply observing the behavior of others.

In the context of information cascades, Bikhchandani et al. $(1992,1998)$ describe that in circumstances where private information is incongruent with publicly observed behavior in the stock market, it is perfectly rational to abandon one's private information in favor of the collective intelligence of the market. Extending the argument, in situations where the best course of action is not obvious, individuals will look to others before making decisions, and will often base those choices on observed behavioral cues.

Adopting the behavior of those around us can be done for several reasons. Bearden et al. (1989) suggest individuals adopt behavior for either information or social reasons. In situations where an individual believes the group possesses a collective information advantage, the person will follow the herd in the hope of obtaining the group's superior information. At other times, an individual will follow the herd in order to fulfill a sub-conscious need to fit into a greater social network. Informational gains and social acceptance are two of the components that combine to create utility in individuals. ${ }^{1}$

In the mortgage markets, an economic default describes a situation when a homeowner defaults on his mortgage due to an inability to make monthly payments, whereas a strategic default is said to occur when a homeowner makes the conscious choice to default on his mortgage when he is fully capable of making his monthly payments. Wheaton and Nechayev (2011) posit that strategic defaults are an innocuous and even necessary clearing mechanism to restore balance in the housing markets. ${ }^{2}$ Alternatively, Wyman (2010), White (2010), FICO (2011), and Guiso et al. (2011) vehemently argue that the increase in strategic defaults is a major contributor to the foreclosure epidemic and resulting stalled economy. ${ }^{3}$ Hence, the purpose of this study is to investigate if/how individuals mimetically herd following the observed behavior of their peers as it relates to the decision to strategically default on one's mortgage.

We find that people's a priori behavior is significantly altered by observing the actions of their peers, and is pronounced in the presence of a Maven, or real estate

\footnotetext{
${ }^{1}$ Too often in academic studies, researchers interchangeably use (and confuse) wealth maximization with utility maximization. Instead, Bearden et al. (1989) argue that people derive utility from wealth, social acceptance, and a myriad of other sources.

${ }^{2}$ The authors state that strategic defaults force lenders to share the responsibility for originating poor loans whereas without these defaults, the financial burden falls squarely on the homeowner. They further explain that additional defaults allow the homeownership rate to return to a more long-run, sustainable level.

${ }^{3}$ Seiler et al. (2011) examine the reasons why people strategically default, while White (2010) suggests possible solutions to the problem.
} 
expert. Conversely, mimetic herding is significantly mitigated when the individual holds a strong moral objection to strategic default, and is not influenced by signal strength. Finally, people tend to herd more for information gains as opposed to social reasons. ${ }^{4}$

\section{Literature Review}

The concept of mimetic herding dates back to Roman times when wealthy families hired individuals to mourn at funerals to create a greater sense of loss due to the passing of the deceased (Bikhchandani et al. 1998). In modern times, knowing that people are genetically predisposed to mimic the behavior of others, comedians plant friends in the audience who laugh early and loudly in the hopes of whipping the crowd into a tickled frenzy. Restaurant owners often close off the back rooms to create the illusion that the food is so good the establishment is filled to capacity. Even the U.S. Navy recognizes the impact of mimetics as it is the current practice to have judges render decisions in reverse order of rank to minimize the tendency of younger judges to follow rulings of older, more established ones. Ben Bernanke also avoids herding by soliciting the opinion of the other members of the Board of Governors before stating his position on economic issues facing the country. ${ }^{5}$ In France and Israel, polls are banned during the weeks leading up to a political election so as not to influence the pattern of voting behavior during the actual election (Farnsworth 2007).

Alevy et al. (2007) discuss how herding is found in fields as varied as medicine, adoption of technology, responses to environmental hazards, and of course, in financial markets. Diamond and Dybvig (1983), Shiller (1990), Eichengreen et al. (1998), Morris and Shin (1999), Bikhchandani and Sharma (2000), Persaud (2000), and Chari and Kehoe (2004) argue that herding adds volatility to the financial markets because these mimicking behaviors cause excessive price movements, or over-reactions, in security prices. The result is an unnecessarily unstable environment. Shiller (2008) argues that herding is responsible for the recent real estate bubble, and suggests that home prices did not need to go nearly as high as they did, and therefore, need not come down as far as they have. ${ }^{6}$ Alternatively stated, in the absence of herding behavior, excessive booms and crashes could be avoided, or at least certainly mitigated.

We are careful to disclose that herding in not necessarily an irrationality argument. Bikhchandani et al. $(1992,1998)$ use Bayesian statistics to mathematically demonstrate that it can be fully rational to abandon private information in favor of the herd if one believes the market possesses a superior collective information set. Two

\footnotetext{
${ }^{4}$ In the current study, we use the term "information gain" to refer to the participant learning more about their peer's willingness to strategically default at varying degrees of being underwater. This is not to be confused with the type of information gain that a participant would use to set efficient prices in a marketplace.

${ }^{5}$ This information was conveyed in a private conversation with a person who regularly meets with Chairman Bernanke. Incidentally, this was not the practice of Alan Greenspan, who spoke first and then asked others if they agreed.

${ }^{6} \mathrm{http}: / /$ www.nytimes.com/2008/03/02/business/02view.html
} 
supporting (yet non-Bayesian) explanations in favor of rational herding are offered by Anderson and Holt (1997) who argue that utility is derived by both social proximity to peer positions and the avoidance of being alone in one's convictions. Interestingly, Keynes (1965) expresses that the positive utility derived from being the only one who is correct is far less than the negative utility experienced when being the only one who is wrong.

Although (too) often used interchangeably in the extant literature, Celen and Kariv (2004) and Chamley (2004) correctly note an important distinction between an information cascade and a herd. While both result in a large number of people making the same decision, in a herd, private information/signals are not necessarily being ignored. Alternatively stated, social learning can take place in a herd, but not in an information cascade where private information is being ignored in favor of the public choices of the group. Whether it is referred to in the literature as herding, information cascades, social contagion, or observational learning, mimetic herding has long been recognized as a means of describing how people influence each other through mere observation. Noting the increased incidence of strategic mortgage default, we seek to test just how malleable homeowners are to the adoption of an advocacy of strategic default.

\section{Experimental Design}

Past studies examining the theory of information cascades and herding can be divided into two classes: regression-based tests using real world data and laboratory experiments using primary data collected from individual participants. ${ }^{7}$ Some experimental studies have relied upon Bayesian statistical experiments involving the drawing of balls from a bag. This type of abstract approach points to the difficulty in investigating theories hoping to discern the behavioral motivations of individuals. In the current investigation, we seek a much more direct investigatory approach to the empirical testing of herding behavior.

The experiment begins by participants being presented with a common setting and set of assumptions as presented in Exhibit 1 (see Appendix). Specifically, participants are assumed to have purchased a home at a price of $\$ 300,000$ making a down payment of $\$ 30,000$ while taking out a fixed rate mortgage. Now, 4 years later, the home has dropped in value to one of nine different levels (Scenarios 1 through 9) leaving the home underwater. ${ }^{8}$ Assuming, the participant does not expect home prices to go up or down at all over the next 3 years, and assuming he is able to continue making his mortgage payments, ${ }^{9}$ we ask the person to share the likelihood

\footnotetext{
${ }^{7}$ Generally, these experiments are done using students, presumably due to their accessibility to researchers.

${ }^{8}$ Wyman (2010), FICO (2011), and Guiso et al. (2011) all conclude that the most deterministic variable in predicting strategic default is the homeowner's negative equity position.

${ }^{9}$ It is important to mention that we do not list the advantages and disadvantages of strategically defaulting on one's mortgage. This list was omitted for several reasons. Firstly, an exhaustive list of pros and cons would be somewhat subjective and very difficult to definitely quantify. Secondly, if we were to explicitly state the pros and cons, we might unintentionally influence the participant responses we so carefully attempt to isolate to the variables examined within the study.
} 
that he will strategically default on his mortgage in each of the scenarios sequentially. ${ }^{10}$

After the participant registers his likelihood of strategically defaulting under the first scenario, a bar chart of the results is shown to reveal the collective responses of past participants (see Exhibit 2 of the Appendix). As such, it is not possible to influence the answers of participants in Scenario 1. Instead, these values are used as a baseline measurement or starting reference point. However, an ability to influence responses is put to the test in all subsequent scenarios. Specifically, in order to measure the differential effects of what each theory would predict, we must carefully create alternative laboratory environments. To accomplish this task, it is necessary to control the feedback the group receives through altering the bar charts. So, while we are able to record the true responses of each participant, we falsely report back to participants a set of behaviors necessary to tease out each specific hypothesis. Walking the participant through each of these nine scenarios constitutes Phase I of the experiment. Phase II uses the exact same scenarios and assumptions, but involves a slightly altered setting. Instead of asking people what they would do in each of the scenarios, participants are asked what they would recommend a friend do in each scenario. To test the various hypotheses, we need a reason to ask the same set of questions as in Phase I. However, to realistically allow for different responses, we need for there to be the possibility that the participant would respond differently between Phases I and II. In sum, our goal is to hold constant the effective settings between the two phases while at the same time plausibly allowing for the participant to observe different collective or aggregated responses. Below, we explain how these effects are controlled for in each successive experimental design variant.

\section{Control Sample}

When considering the various hypotheses to be tested and the control measures that need to be in place, it is necessary to create 50 distinct deviations from our base experiment. The base experiment involves each participant (within this control sample group) walking through each of the phases and indicating their likelihood of defaulting without receiving any feedback concerning the responses of other participants. This control group enables us to see how participants respond in the absence of feedback manipulations. Beyond the control group, the (falsely) reported group responses are constructed in multiple ways to isolate each particular theory as discussed below.

\section{Skewing Order}

We posit that people can be swayed from their a priori actions and opinions simply by observing a different behavior from others around them. This issue is

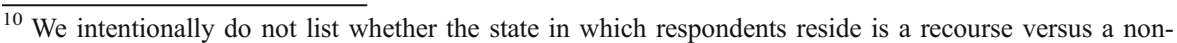
recourse state because it is unlikely that individual homeowners know what this difference means for them on a practical level (Guiso et al. 2011). And even if homeowners did understand the difference, the current experience is that lenders are not pursuing deficiency judgments anyway. In general, adding too many variables to the list for homeowners to consider in their decision whether or not to strategically default may start to overwhelm them. Instead, we focus on the aforementioned considerations that we deem are most important based on the works of Guiso et al. (2011) and Seiler et al. (2011).
} 
examined by falsely reporting extremely low group mean responses (low likelihood of strategically defaulting) in one of the phases and extremely high group mean responses (high likelihood of strategically defaulting) in another. Skewing order simply refers to whether the high means are shown in Phase 1 or Phase 2. As a random design variable, we do not expect skewing order to be significant.

\section{Presentation Order}

In constructing the base experimental design, we associate Phase I with the likelihood of the participant defaulting, while in Phase II, we change the setting to reference advice given to the participant's friend. The base design also uses low-mean graphs in Phase I, and high-mean graphs in Phase II. To avoid problems with order effects, we then randomize the order in which these controls appear so as not to systematically influence the results.

\section{Signal Strength}

The next variation in the design relates to the strength of the herding signal implied through the shape of the distribution of participant responses. A strong signal is seen when the group's answers converge around the mean score resulting in a tall and tight distribution of responses (a leptokurtotic distribution). In this case, Hirshleifer et al. (1994) predict the participant may feel compelled to express the same view even though he may not share it. Conversely, a weak signal is seen when the group's responses are spread out more evenly across the 9-point "likelihood of default" scale (a platykurtotic distribution). Jegadeesh and Kim (2010) suggest less herding in this situation because individuals are implicitly given greater freedom to choose any score they want. Alternatively, Fernández et al. (2011) interpret a wider dispersion in the distribution of participant responses as being reflective of a more uncertain market environment. If this is the case, the uncertainty would be a reason for participants to herd more, not less. Based on the competing predictions in the extant literature, we leave the sign on the signal strength variable as an empirical question.

To hold all else constant and truly isolate the effect of signal strength, it is necessary to create a set of graphs whose mean is the same between both groups, but whose distribution is tight for one group and wide for another. We do this for all nine scenarios and across both phases. An example of the signal strength design is illustrated in Exhibit 3 (see Appendix).

The central hypothesis in this study is that the (falsely) reported aggregated responses will significantly impact participant indications of likelihood of strategically defaulting in each successive scenario. We further control for various order effects in the experimental design to remove potential confounding of the results. Until this point in the paper, we have only discussed variations of the experiment where the bar charts reflect previous participant's likelihood of strategic default indications. We next extend our discussion to variations in the design which consider the influence that specific individuals might have on the results. 


\section{Maven Influencer}

A "Maven" is an expert or knowledge leader in a particular subject (Feick and Price 1987). These are individuals whose opinions are sought particularly when the decision to be made is complex and/or ambiguous. We hypothesize that observing the behavior/choice of a Maven will have a greater influence on participants than observing the behavior of an average person. To test this hypothesis, we create a variation of the design where after each scenario, in addition to reporting (false) group responses, we also report the response from a real estate expert.

Based on Engelberg and Parsons (2011), 18 major newspapers from across the United States were identified-one for each of the scenarios $(9 \times 2)$. We then selected 18 last names, 9 male first names and 9 female first names. Using a Fisher and Yates $(1938)^{11}$ shuffling algorithm to ensure proper randomization of draws without replacement, we then assigned a full reporter name to each newspaper. In this variant of the experiment, participants saw not only falsified means and a corresponding bar chart for each scenario, they also saw the exact score associated with a Maven from a leading newspaper. To be sure the Maven effect is consistent with the High-Low skewing effect, the Maven's score was randomly selected from integers strictly greater (less) than the reported mean in the High (Low) graph phase. Exhibit 4 (see Appendix) reports the newspapers and reporter names utilized in this study.

\section{Participant (Non-Maven) Influencer}

White (2010) and Seiler et al. (2011) demonstrate that there are substantial levels of shame associated with the act of strategically defaulting. Thus far, individual responses have not been publicly associated with a particular individual. If we introduce the possibility that participant's likelihood of default scores will be shown to others in the experiment, we would expect people to express a lesser willingness to strategically default or at least a lesser willingness to break away from the herd. To carry out this variation in design, we begin by collecting the names of participants entering the experiment and convey that their responses have a $(1 / \mathrm{n})$ random chance of being shared along with their name, city and state with future participants. ${ }^{12}$ We then use the same Fisher and Yates (1938) algorithm to randomize the 18 fictitious name combinations shown in Exhibit 4 (see Appendix). In this sub-sample, after the participant answers each scenario, they see the (falsely) aggregated responses of those before them as well as what they believe to be a randomly selected past participant, that participant's city and state, as well as their likelihood of strategic default score for that scenario. The city and state names were randomly selected from our populationweighted database.

\footnotetext{
${ }^{11}$ The computer version of this algorithm was popularized by Knuth (1969) in volume 2 of his book.

${ }^{12}$ While we do not actually share their names and corresponding responses (due to Institutional Review Board restrictions), simply imposing a credible belief that revelation is a real possibility is sufficient to maintain the integrity of the test.
} 
To clarify the experimental design, each participant is exposed to just one of the 50 variant combinations discussed above. As such, we are following a "between subjects" design. The 50 variant combinations of the study are graphically presented in Exhibit 5 (see Appendix).

\section{Methodology}

We seek to measure how susceptible people are to changing their responses based on outside influences. Due to our unique design, we create Mimetic Herding scores in several different ways to examine the issue from different perspectives. First, we create Mimetic Herding scores for a given respondent by taking the absolute difference between their Phase II and Phase I responses. Due to the controlled environment, we are able to attribute the reason for these potential shifts from one phase to the next to controls within our model. Next, we create Mimetic Herding scores at the scenario level by comparing responses to the corresponding answers from the control sample. Control sample means make sense because they represent a good proxy for how the participants likely would have responded in the absence of our experimental controls. Finally, we create Mimetic Herding scores at the scenario level by comparing responses to the fabricated mean values shown to respondents during the experiment. These reported means are appropriate in the sense that they were perceived by participants to be the true mean responses of their peers. These three techniques enable us to clearly identify the amount of mimetic herding that occurs.

For our initial measure of Mimetic Herding, we are interested in the deviation of a respondent's answer on a given question $q_{1}$ from Phase I with the respondent's answer on the corresponding question $r_{1}$ from Phase II. For a question $q$, take individual $i$ in group $j$ (either $A$ for Aggregated Responses Influencer group, $M$ for Maven Influencer group, $P$ for Participant Influencer group), to have a private belief $\mathrm{x}_{i j q}$ about the appropriate answer for the question. The Mimetic Herding Score, $\theta_{j q}$, for group $j$, question $q$ is then

$$
\text { Mimetic Herding Scor } e_{1} \quad \theta_{j q}=A B S\left(x_{i j q}-x_{i j r}\right)
$$

where, $x_{i j r}$ is the respondent's answer to question $r$, which is the corollary to question $q$, but is from Phase II. The MSE, $\vartheta_{j q}^{2}$, for group $j$, question $q$, is then

$$
\vartheta_{j q}^{2}=\frac{1}{N_{j}} \sum_{i=1}^{N_{j}}\left(A B S\left(x_{i j q}-x_{i j r}\right)-\bar{x}_{i j q r}\right)^{2}
$$

where, $\mathrm{N}_{j}$ is the number of group $j$ members in the sample and $x_{i j r}$ is the participant's answer to question $r$, which is the corollary to question $q$, but is from Phase II, and $\bar{x}_{i j q r}$ is the mean of the absolute value series. A group that is exhibiting Mimetic Herding will have a higher MSE for that question. 
For our second measure of Mimetic Herding, we are interested in the deviation of a respondent's answer on a given question $q$ from the control sample's response on question $q$. To create our measure of Mimetic Herding, we use a squared deviation from the mean approach similar to Healy (2009), as follows. For a question $q$, take individual $i$ in group $j$ (either $A$ for Aggregated Responses, $M$ for Maven Influencer group, or $P$ for Participant Influencer group), to have a private belief $\mathrm{x}_{i j q}$ about the appropriate answer for the question. The Mimetic Herding score for group $j$, question $q$ is then

$$
\text { Mimetic Herding Score } e_{2} \quad \phi_{j q}=\left(x_{i j q}-\text { Control }_{q}\right)^{2}
$$

where, Control $_{q}$ is the control sample's answer for question $q$. The MSE, $\Delta_{j q}^{2}$, for a group $j$, question $q$ is then

$$
\Delta_{j q}^{2}=\frac{1}{N_{j}} \sum_{i=1}^{N_{j}}\left(x_{i j q}-\text { Control }_{q}\right)^{2}
$$

where, $\mathrm{N}_{j}$ is the number of group $j$ members in the sample and Control $_{q}$ is the control sample's answer for question $q$. A group that is exhibiting Mimetic Herding will have a higher MSE for that question.

For our final measure of Mimetic Herding, we are interested in the deviation of a respondent's answer on a given question $q$ from the mean response shown to the respondent on question $q$. For question $q$, take individual $i$ in group $j$ (either $A$ for Aggregated Responses, $M$ for Maven Influencer group, or $P$ for Participant Influencer group), to have a private belief $\mathrm{x}_{i j q}$ about the appropriate answer for the question. The Mimetic Herding score for group $j$, question $q$ is then

$$
\text { Mimetic Herding Score } \text { S }_{3 q}=\left(\chi_{i j q}-\operatorname{AggrResp}_{q}\right)^{2}
$$

where, $\operatorname{AggrResp}_{q}$ is the value that was reported as being the mean answer given by previous survey participants for that question. The MSE, $\delta_{j q}^{2}$, for group $j$, question $q$ is then

$$
\delta_{j q}^{2}=\frac{1}{N_{j}} \sum_{i=1}^{N_{j}}\left(x_{i j q}-\operatorname{AggrResp}\right)^{2}
$$

where, $\mathrm{N}_{j}$ is the number of group $j$ members in the sample and $\operatorname{AggrResp} p_{q}$ is the value that was reported as being the mean answer given by previous survey participants for question $q$. A group that is exhibiting Mimetic Herding will have a lower MSE for that question.

Now that the three Mimetic Herding scores have been created, we next specify a model to explain these scores as follows:

Mimetic Herding $=f\{$ Experimental Design Controls, Miscellaneous, Demographics $\}$ 


\section{where the specific variables are defined as:}

Dependent Variables: Mimetic Herding

Mimetic Herding Score-1 Absolute difference between Phase I and Phase II scores for each of the final eight scenarios

Mimetic Herding Score-2 Mimetic Herding Scores using the control group means

Mimetic Herding Score-3 Mimetic Herding Scores using the fabricated means

Independent Variables: Experimental Design Controls

Skewing Order

Refers to the scenario averages experimenters inserted in an attempt to herd participant scores either higher or lower. $1=$ high means; $0=$ low means.

Presentation Order

Refers to whether phase 1 of the experiment referred to the actions the participant would do if she were in the situation versus what they would recommend their friend would do. $0=$ you; $1=$ friend.

Signal Strength

Refers to the situation where the distribution of past participant responses was falsely reported to be extremely tightly centered about the mean (leptokurtotic). 1 = a Tight-Tight, 0 otherwise. ${ }^{13}$

Maven Influencer A dummy variable equal to 1 if an expert opinion was seen by the current participant, 0 otherwise.

Participant Influencer A dummy variable equal to 1 if a past participant opinion was seen by the current participant, 0 otherwise.

Independent Variables: Miscellaneous

Can Be Easily Influenced Refers to how easily the participant thinks his answers can be influenced by others from 1 (not easily influenced) to 9 (easily influenced).

Real Estate Knowledge

The self-assessed level of knowledge from 1 (not knowledgeable) to 9 (very knowledgeable).

Susceptibility to Informational The self-assessed level of malleability due to information gains from Influence (SII) 1 (not malleable) to 9 (very malleable) based on Bearden et al. (1989).

Susceptibility to Normative Influence (SNI)

The self-assessed level of malleability due to the social need to fit in from 1 (not malleable) to 9 (very malleable) based on Bearden et al. (1989).

Moral Viewpoint

The degree to which the participant believes it is morally wrong to strategically default on one's mortgage from 1 (not wrong) to 9 (very wrong).

Independent Variables: Demographics

Age

Age

Number of Children under 18

Children under 18 Dummy

The number of children under the age of 18

Education Level

1 if the participant has at least one child under the age of 18,0 otherwise

College Dummy

$1=$ Ph.D.; 2 = Master's Degree; 3 = Bachelor's Degree; 4 = Some college;

$5=$ High School Diploma; and $6=$ Less than High School Diploma

Ethnicity:

1 if the participant has a college degree, 0 otherwise

1 = African American; 2 = Asian; $3=$ Caucasian; $4=$ Hispanic; $5=$ Native American; $6=$ other

Male Dummy

1 if the participant is a male, 0 otherwise

Income

The participant's income expressed as an increasing function across seven $\$ 20,000$ buckets.

Single Dummy

1 if the participant is single, 0 otherwise

Net Worth

The participant's net worth expressed as an increasing function across nine $\$ 200,000$ buckets ranging from less than $-\$ 400,000$ through over $\$ 1,000,000$

Positive Net Worth Dummy 1 if the participant has a positive net worth, 0 otherwise

$\overline{{ }^{13} \text { Alternative specifications, such }}$ as letting $1=$ tight-tight and $0=$ wide-wide, yield qualitatively similar results. 


\section{Data}

Data from this study were collected in the last week of March 2011, using an existing online network of homeowners who stand ready to complete Web-based experiments. Our Institute simply posts a notice on the server for a task we would like to be performed and lets potential participants self-select into the pool. Participants hail from all across the United States and generally reflect the overall population of U.S. homeowners ${ }^{14}$ with the exception that our participants are somewhat younger and have attained a higher level of education. ${ }^{15}$ Originally, 1,495 individuals participated in our experiment. However, after screening the data, the final sample consists of 1,365 usable responses.

Most economic experiments use a reward-based system where compensation is tied to the correctness of the answers provided by participants. However, in the context of strategic default, there truly are no "correct" answers. We merely collect data on people's strategic default acceptance threshold. As such, it is not possible to tie compensation to participant responses in a meaningful way. Instead, we posted the experiment with a flat participation fee of $\$ 2.06,{ }^{16}$ an amount large enough to encourage participation, but not so large as to attract people who might engage for the wrong reasons.

Having collected data from this general pool of participants for a multitude of different studies in the past, we have evolved an intricate screening system to ensure cleaner tests of our hypotheses. Concerning missing data, we screen to be sure participants answered all 18 default scenarios in order to obtain a complete picture of each person's strategic default acceptance threshold. Further, at two different places within the experiment, we ask the person to answer a certain number, say " 3 ," for one question and say "7," for another. This simple technique ensures participants are at least reading the questions carefully. ${ }^{17}$ Moreover, we place a hidden timer in the experiment to record the time it took for the person to read the instructions. If the person advances the screen before 10 seconds have elapsed, we discard all their responses. ${ }^{18}$ Another technique to identify people who do not take the experiment seriously is to have them begin the experiment by selecting their city and state from a pull-down menu early in the experiment. Then, at the end of the experiment, we ask them for their zip code. ${ }^{19}$ If the two do not match up, we remove them from the final sample.

In addition to the above methods, we also have the ability to require participants to have an overall service satisfaction rating of no less than $95 \%$ on past tasks

\footnotetext{
${ }^{14}$ See Seiler et al. (2011) for a detailed discussion of this data source and how it matches up with the population of homeowners across the United States.

${ }^{15}$ This profile of being somewhat younger and more educated is likely an artifact of having the experiment completed on-line.

${ }^{16}$ Because potential participants can sort tasks by compensation amount, we employ auction theory by selecting an amount slightly above two dollars to place our task higher on the list, and thus gain greater awareness by potential participants.

${ }^{17}$ Reading instructions carefully is a necessary, but not sufficient condition to guarantee comprehension of the experiment. However, given the consistency in responses as the degree of being underwater increases, it is reasonable to assume that participants understood the experiment.

${ }^{18}$ It is important to note that the participants do not know we are timing them. This timer is hidden so as to avoid any awareness of their part to "game" the system.

${ }^{19}$ We do not allow backtracking through the experiment at this point. Thus, there is no way for the participant to go back and see which city and state they selected. The odds of a person randomly selecting a city and state, remembering later what they selected, and then looking up a proper zip code within that city would seem very low indeed.
} 
completed for us and other posting organizations. To clarify, participants are approved (or disapproved) by each posting organization for having performed sufficiently (insufficiently) on a given task. These ratings are made available to all subsequent posting organizations so that they may choose to disallow people from performing tasks for them in the future. On an individual organization level, we have also built in screens to permanently block people who do not meet our series of screens in past experiments from ever participating in future experiments for us. We accomplish this by banning the unique individual identifiers created when a person signs up to create an account.

Beyond individual task evaluations, we further identify those who do not fully engage in the experiment by cross-referencing the demographic data from the current collection effort to those we have collected in the past. If the person's unique identifying number has been used in a past study, we are able to cross-reference their demographic data and run further screens to see if these reported values have unrealistically changed. If, for example, a person reports different genders or nationalities from one experiment to the next, a red flag is sent up to identify the person as falsifying their responses. These folks would be permanently banned from our individualized pool.

Readers might be concerned that people within this system may have created multiple accounts using multiple e-mail addresses, and as such, may have participated in our current experiment multiple times. This is highly unlikely given that in order to establish an account within this system, an active credit card matching the name of the accountholder must be provided. Moreover, once a person completes our experiment, they are unable to re-enter the task. Importantly, if a person were to complete the same task multiple times, it would seem reasonable to assume they were doing so for the money. As such, they would be likely to want to hurry through the experiment, taking as little time as possible to discern the intricacies of our experimental design. Consequently, this type of behavior would work toward a null result, not towards a significant finding. In sum, as with any experimental design, it is in our best interest to produce as pure an experimental environment as possible if we hope to definitively answer our research questions. Table 1 provides descriptive statistics for the sample.

\section{Results}

To learn how participants might have responded in the absence of our experimental manipulations of the environment, we begin by analyzing data collected from a control group. Panel A of Table 2 reports that their uninfluenced scores range from a low of 1.62 (not likely to strategically default) up to 6.99 (more likely to strategically default). The shape of the progression moving from lower scenarios (where the home is not far underwater) to higher scenarios (where the home is extremely far underwater) is upward sloping as hypothesized. From a design perspective, it is fundamentally sound to see results that are not compressed against either the ceiling or floor of the scale. These baseline scores can more formally be interpreted as the person's strategic default acceptance threshold.

Panel B reports the fabricated means that were shown to all other participants (not the control group). In Panel $\mathrm{C}$, we begin to examine the data using simple univariate techniques. First, the low versus high means are considered. Note that in this single- 
Table 1 Descriptive statistics

\begin{tabular}{|c|c|c|c|c|}
\hline Cleaned sample $(N=1,365)$ & Minimum & Maximum & Mean & Standard deviation \\
\hline Answers easily influenced by others & 1 & 9 & 4.04 & 2.28 \\
\hline Knowledgeable about real estate & 1 & 9 & 4.52 & 1.97 \\
\hline Susceptibility to informational influence (SII) & 1 & 9 & 4.57 & 2.15 \\
\hline Susceptibility to normative influence (SNI) & 1 & 9 & 6.75 & 1.83 \\
\hline Know a strategic defaulter & 1 & 9 & 3.42 & 3.01 \\
\hline It is morally wrong to strategically default & 1 & 9 & 5.17 & 2.54 \\
\hline \multicolumn{5}{|l|}{ Demographics } \\
\hline Age & 18 & 72 & 31.71 & 10.66 \\
\hline Number of children under 18 & 0 & 7 & 0.67 & 1.11 \\
\hline Children under 18 dummy & 0 & 1 & $33.92 \%$ & 0.34 \\
\hline Education level & 1 & 6 & 3.38 & 0.91 \\
\hline College dummy & 0 & 1 & $53.04 \%$ & 0.50 \\
\hline \multicolumn{5}{|l|}{ Ethnicity: } \\
\hline African American & & & $5.1 \%$ & \\
\hline Asian & & & $9.4 \%$ & \\
\hline Caucasian & & & $80.1 \%$ & \\
\hline Hispanic & & & $3.2 \%$ & \\
\hline Native American & & & $1.1 \%$ & \\
\hline Other & & & $0.8 \%$ & \\
\hline Male dummy & 0 & 1 & $46.45 \%$ & 0.50 \\
\hline Income & 1 & 7 & 2.79 & 1.57 \\
\hline Single dummy & 0 & 1 & $53.76 \%$ & 0.50 \\
\hline Net worth & 1 & 9 & 3.55 & 1.68 \\
\hline Positive net worth dummy & 0 & 1 & $63.24 \%$ & 0.48 \\
\hline
\end{tabular}

This table displays descriptive summary statistics (minimum, maximum, mean and standard deviation) for key variables of interest for participants included in the final study. Answers easily influenced by others reports how easily the participant thinks his answers can be influenced by others from 1 (not easily influenced) to 9 (easily influenced). Knowledge about real estate reports the self-assessed level of knowledge from 1 (not knowledgeable) to 9 (very knowledgeable). Susceptibility to Informational Influence (SII) captures the selfassessed level of malleability due to information gains from 1 (not malleable) to 9 (very malleable). Susceptibility to Normative Influence (SNI) captures the self-assessed level of malleability due to the social need to fit in from 1 (not malleable) to 9 (very malleable). Know a strategic defaulter reflects the degree to which the participant agrees with the statement that he knows someone who has strategically defaulted on his mortgage from 1 (do not know) to 9 (do know). It is morally wrong to strategically default reflects the degree to which the participant believes it is morally wrong to strategically default on ones mortgage from 1 (not wrong) to 9 (very wrong). Age is the age of the participant. Number of Children under 18 reports the number of children living at home under the age of 18 years old. Children under 18 Dummy is a dummy variable equal to 1 if the participant has at least one child under the age of 18 who lives at home with them. Education Level reflects the participant's highest attainted education level where $1=$ Ph.D.; 2 = Master's Degree; 3 = Bachelor's Degree; 4 = Some college; 5 = High School Diploma; and $6=$ Less than High School Diploma. College Dummy is equal to 1 if the participant has a college degree. Male Dummy is a dummy variable equal to 1 if the participant is a male. Income is the participant's income expressed as an increasing function across seven $\$ 20,000$ buckets. Single Dummy is a dummy variable equal to 1 if the participant is single. Net Worth is the participant's net worth expressed as an increasing function across nine $\$ 200,000$ buckets ranging from less than $-\$ 400,000$ through over $\$ 1,000,000$. Positive Net Worth Dummy is a dummy equal to 1 if the participant has positive net worth. For all the dummy variables, the "otherwise" case is set equal to zero 


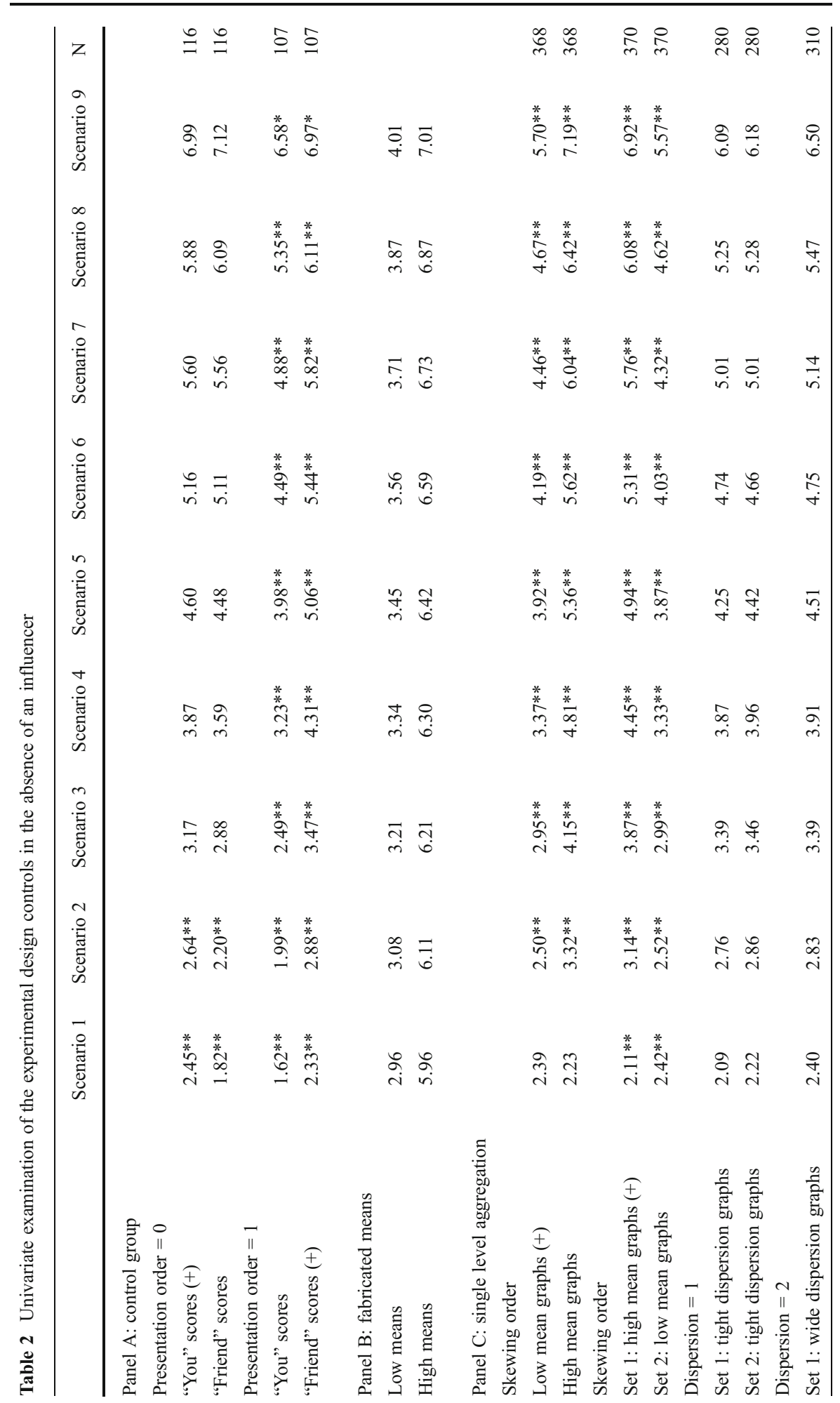




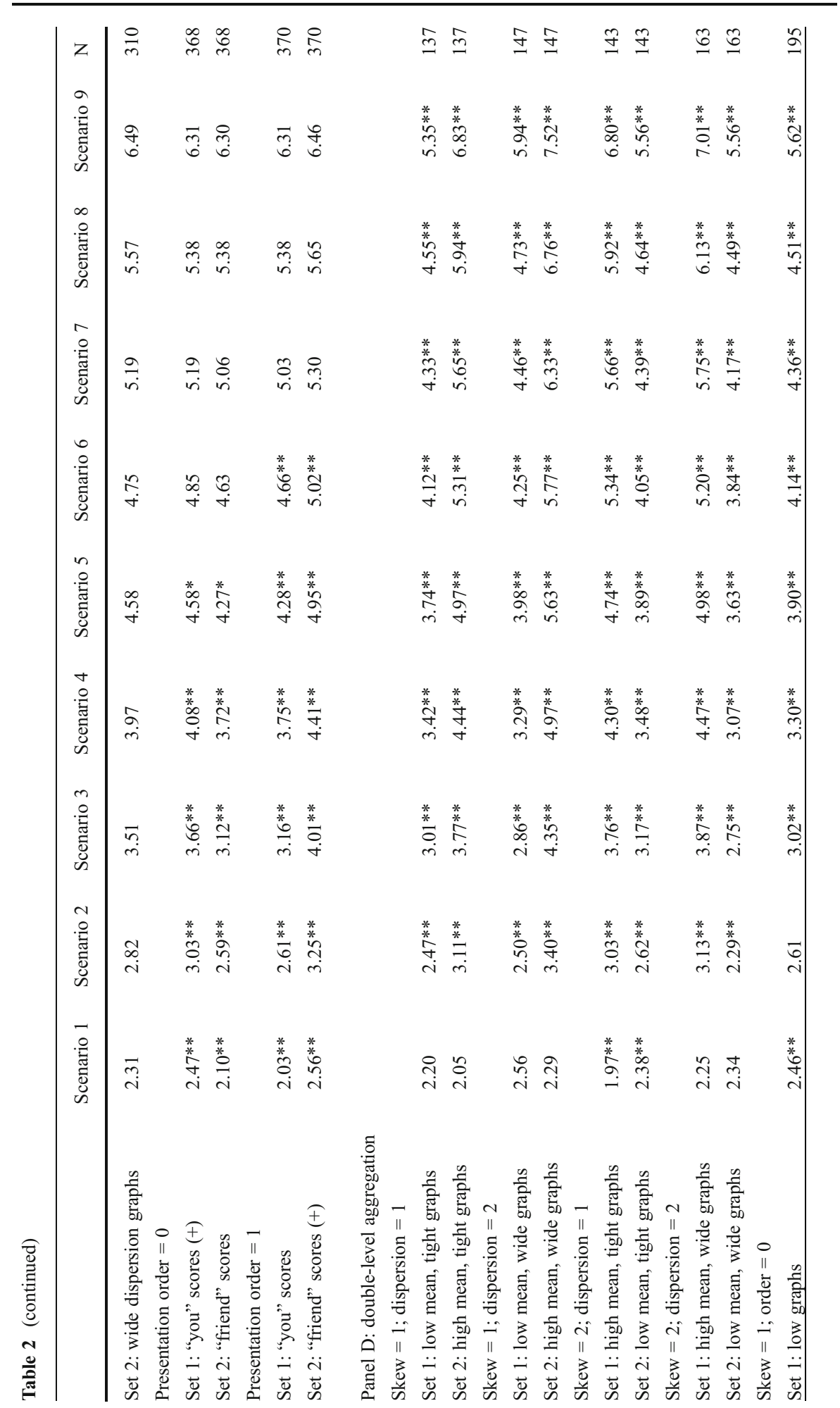




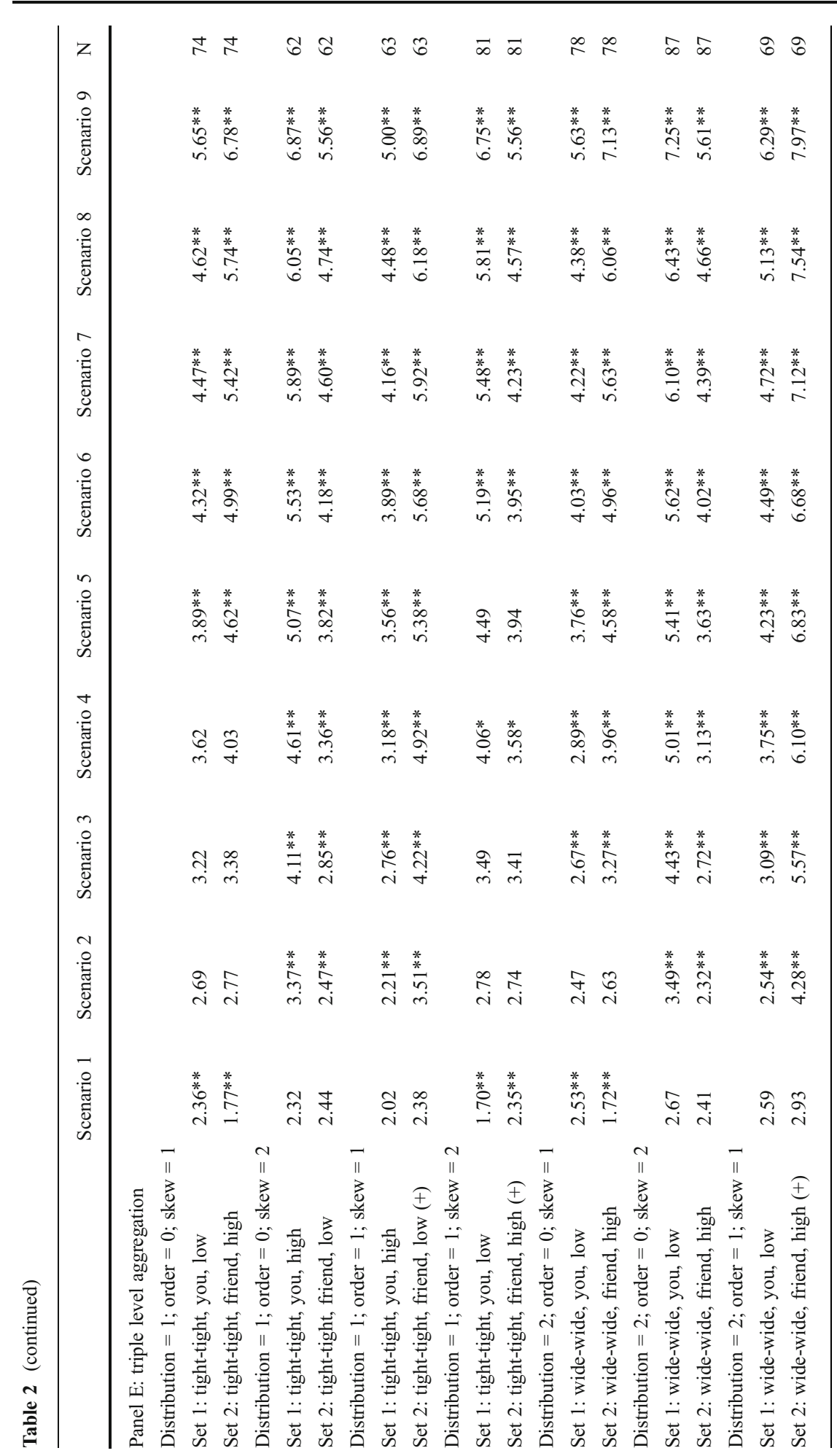




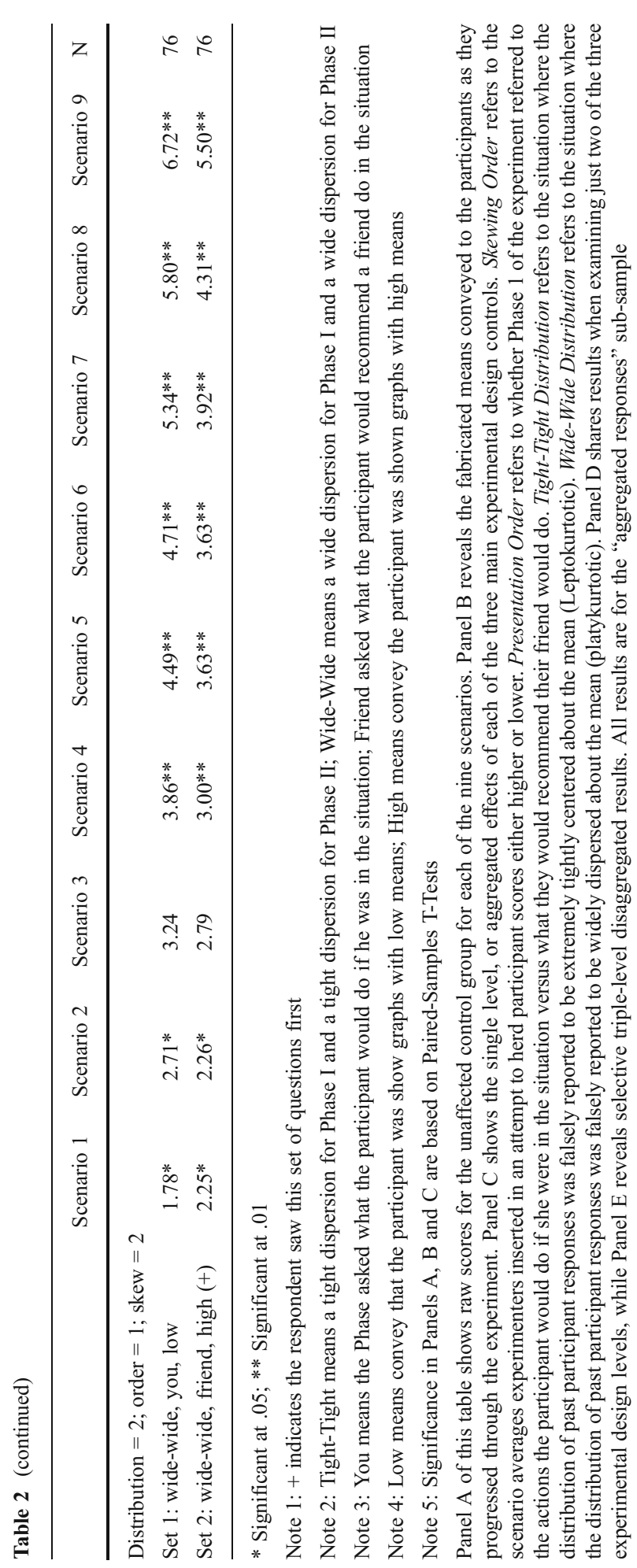


level aggregation, all other influences are mixed in with the low versus high means. Therefore, interpretation of the results must be met with caution. Panel C is simply being reported to get an initial feel for the data.

Paired-Samples T-Tests report significance in almost all high versus low skewing scenarios indicating that participants might have been swayed from their unbiased estimates based on seeing (fabricated) collective results that were artificially presented as being extremely high or low. Scores are statistically similar when considering the single-aggregation effect of the distribution of past responses (leptokurtosis versus platykurtosis). Early indications are, therefore, that participants were not affected by the degree of dispersion of responses about the mean (signal strength). Concerning presentation order, it appears that whichever group went first had higher reported values. This did not matter whether the phase asked about the participant or the participant's friend. This presentation order is consistent with the effect seen in the control group as well. Observing an order effect is another confirmation that the steps taken to control the experimental design were necessary to isolate the key variables of interest-skewing and signal strength. Panels D and E present secondary and tertiary dissections of the likelihood of strategic default by the three control variables. These breakdowns support earlier indications that presentation order and skewing matter, but not so much the strength of the signal.

Table 3 presents a correlation matrix of potential independent variables used in the regression analyses to follow. Most of the demographic variables are intuitively linked. For example, married participants are associated with being slightly older, more likely to have graduated college, make more money and have greater wealth, have children, and so forth. Moving away from demographics, people who believe they can more easily be influenced, have lower self-assessed levels of knowledge, and rate higher on the Susceptibility to Normative Influence scale. But, again, none of the correlation coefficients send up a red flag in terms of multicollinearity problems moving forward. ${ }^{20}$

Exhibits 6 and 7 (see Appendix) visually present the results of our central hypotheses in the paper. Exhibit 6 (see Appendix) shows the average mimetic herding scores for the main sample relative to the control sample's responses on each question. The upward trend shows strong evidence that the respondent's answers were pulled farther and farther from the control sample's responses on each question. This is clear evidence of mimetic herding. Exhibit 7 (see Appendix) shows the average mimetic herding scores for the main sample relative to the fabricated means that the participant observed on each question. The downward trend shows that the homeowner's answers were pulled closer to the fabricated means over time again providing evidence of mimetic herding.

Table 4 provides a direct multivariate test of our central hypotheses in the paper. We specify the measure of Mimetic Herding as the absolute difference in participant scores between the first and second phases of the experiment. ${ }^{21}$ As hypothesized, the presence of a Maven significantly encourages herding well beyond the $99 \%$ level.

\footnotetext{
${ }^{20}$ Note that in the regressions, we perform more complex and direct tests for multicollinearity such as Variance Inflation Factors (VIF), Tolerance and Condition Indexes. For a more detailed discussed see Seiler (2004).

${ }^{21}$ The coefficients and significance levels for all variables in the model are qualitatively similar to the results reported here whether randomized design variables (skewing order and presentation order) are included or not.
} 
Table 3 Correlation matrix for independent variables subsequently used to explain mimetic herding

\begin{tabular}{|c|c|c|c|c|c|c|c|c|c|c|c|c|}
\hline & Know & SII & SNI & Morals & Age & Child & College & White & Male & Income & Single & PosNW \\
\hline Easy & -.269 & .220 & .349 & -.094 & -.220 & -.108 & -.057 & -.061 & .067 & -.164 & .192 & -.072 \\
\hline Know & & -.202 & .000 & .080 & .154 & .129 & .105 & -.035 & .081 & .240 & -.161 & .171 \\
\hline SII & & & .225 & .003 & -.165 & -.056 & -0.44 & -.026 & -.013 & -.144 & .072 & -.118 \\
\hline SNI & & & & .038 & -.245 & -.044 & -.047 & -.083 & .066 & -0.81 & .134 & -.083 \\
\hline Morals & & & & & .126 & .041 & .056 & .021 & -.165 & .106 & -.124 & .077 \\
\hline Age & & & & & & .078 & .148 & .121 & -.131 & .297 & -.345 & .190 \\
\hline Child & & & & & & & -.130 & .012 & -.116 & .216 & -.392 & .018 \\
\hline College & & & & & & & & -.053 & -.021 & .305 & -.071 & .234 \\
\hline White & & & & & & & & & .017 & .010 & -.094 & -.011 \\
\hline Male & & & & & & & & & & -.055 & .197 & .031 \\
\hline Income & & & & & & & & & & & -.366 & .440 \\
\hline Single & & & & & & & & & & & & -.135 \\
\hline
\end{tabular}

This table reports the correlation coefficients for each of the six miscellaneous predictors as well as the eight demographic variables. Easy reports how easily the participant thinks his answers can be influenced by others from 1 (not easily influenced) to 9 (easily influenced). Know reports the self-assessed level of knowledge from 1 (not knowledgeable) to 9 (very knowledgeable). SII (Susceptibility to Informational Influence) captures the self-assessed level of malleability due to information gains from 1 (not malleable) to 9 (very malleable). SNI (Susceptibility to Normative Influence) captures the self-assessed level of malleability due to the social need to fit in from 1 (not malleable) to 9 (very malleable). Morals reflects the degree to which the participant believes it is morally wrong to strategically default on ones mortgage from 1 (not wrong) to 9 (very wrong). Age is the age of the participant. Child is a dummy variable equal to 1 if the participant has at least one child under the age of 18 who lives at home with them. College is equal to 1 if the participant has a college degree. White is a dummy variable equal to 1 if the participant is Caucasian. Male is a dummy variable equal to 1 if the participant is a male. Income is the participant's income expressed as an increasing function across seven $\$ 20,000$ buckets. Single is a dummy variable equal to 1 if the participant is single. $\operatorname{Pos} N W$ is a dummy equal to 1 if the participant has positive net worth. For all the dummy variables, the "otherwise" case is set equal to zero

However, signal strength does not differentially invoke herding. Interestingly, people who thought their behavior could be influenced by others were correct. Based on susceptibility to information influence (SII) and susceptibility to normative influence (SNI) measures developed by Bearden et al. (1989), it appears participants herd more for informational gains as opposed to social reasons. ${ }^{22}$ Finally, as hypothesized, herding behavior is significantly mitigated when the person holds a moral objection to strategic default.

While Table 4 examines herding behavior scenario by scenario, in Table 5 we use the Healy (2009) inspired sum of squared distance from the mean measure to calculate an accumulated Mimetic Herding score that aggregates static measurements across each of the eight scenarios. ${ }^{23}$ Mimetic herding is said to increase when the

\footnotetext{
${ }^{22}$ Again, note that the information being gained here refers to the participant learning of his peers' willingness to strategically default under 9 different scenarios, each associated with being progressively further underwater in their mortgage.

23 Again, we omit the first scenario as it is not possible to influence the participant until after he has seen the first graph-which appears after he has indicated his likelihood of strategic default in the first scenario.
} 
Table 4 Regressions to explain mimetic herding

\begin{tabular}{|c|c|c|c|c|c|c|c|c|}
\hline & $\begin{array}{l}\text { Scenario } \\
2\end{array}$ & $\begin{array}{l}\text { Scenario } \\
3\end{array}$ & $\begin{array}{l}\text { Scenario } \\
4\end{array}$ & $\begin{array}{l}\text { Scenario } \\
5\end{array}$ & $\begin{array}{l}\text { Scenario } \\
6\end{array}$ & $\begin{array}{l}\text { Scenario } \\
7\end{array}$ & $\begin{array}{l}\text { Scenario } \\
8\end{array}$ & $\begin{array}{l}\text { Scenario } \\
9\end{array}$ \\
\hline Skewing order & $\begin{array}{l}-.121 \\
(.094)\end{array}$ & $\begin{array}{l}-.088 \\
(.099)\end{array}$ & $\begin{array}{l}-.147 \\
(.103)\end{array}$ & $\begin{array}{l}-.071 \\
(.106)\end{array}$ & $\begin{array}{l}.039 \\
(.105)\end{array}$ & $\begin{array}{l}.029 \\
(.110)\end{array}$ & $\begin{array}{l}-.041 \\
(.114)\end{array}$ & $\begin{array}{l}.026 \\
(.125)\end{array}$ \\
\hline $\begin{array}{l}\text { Presentation } \\
\text { order }\end{array}$ & $\begin{array}{l}.283^{* *} \\
(.094)\end{array}$ & $\begin{array}{l}.400 * * \\
(.099)\end{array}$ & $\begin{array}{l}.235^{*} \\
(.103)\end{array}$ & $\begin{array}{l}.306^{* *} \\
(.106)\end{array}$ & $\begin{array}{l}.286^{* *} \\
(.105)\end{array}$ & $\begin{array}{l}.393 * * \\
(.110)\end{array}$ & $\begin{array}{l}.362 * * \\
(.114)\end{array}$ & $\begin{array}{l}.315^{*} \\
(.126)\end{array}$ \\
\hline Signal strength & $\begin{array}{l}-.175 \\
(.096)\end{array}$ & $\begin{array}{c}-.224 * \\
(.102)\end{array}$ & $\begin{array}{l}-.203 \\
(.105)\end{array}$ & $\begin{array}{l}-.048 \\
(.109)\end{array}$ & $\begin{array}{l}-.013 \\
(.107)\end{array}$ & $\begin{array}{l}-.019 \\
(.112)\end{array}$ & $\begin{array}{l}-.108 \\
(.116)\end{array}$ & $\begin{array}{l}-.015 \\
(.128)\end{array}$ \\
\hline Maven influencer & $\begin{array}{l}.412^{* *} \\
(.120)\end{array}$ & $\begin{array}{l}.519^{* *} \\
(.127)\end{array}$ & $\begin{array}{l}.606^{* *} \\
(.132)\end{array}$ & $\begin{array}{l}.614^{* *} \\
(.135)\end{array}$ & $\begin{array}{l}.527^{* *} \\
(.134)\end{array}$ & $\begin{array}{l}.520 * * \\
(.140)\end{array}$ & $\begin{array}{l}.662 * * \\
(.145)\end{array}$ & $\begin{array}{l}.614 * * \\
(.160)\end{array}$ \\
\hline $\begin{array}{l}\text { Participant } \\
\text { influencer }\end{array}$ & $\begin{array}{c}.028 \\
(.133)\end{array}$ & $\begin{array}{c}.191 \\
(.141)\end{array}$ & $\begin{array}{c}.166 \\
(.146)\end{array}$ & $\begin{array}{c}.229 \\
(.151)\end{array}$ & $\begin{array}{c}.091 \\
(.149)\end{array}$ & $\begin{array}{c}.145 \\
(.156)\end{array}$ & $\begin{array}{c}.197 \\
(.161)\end{array}$ & $\begin{array}{c}.079 \\
(.178)\end{array}$ \\
\hline $\begin{array}{c}\text { Can be easily } \\
\text { influenced }\end{array}$ & $\begin{array}{l}.122 * * \\
(.023)\end{array}$ & $\begin{array}{l}.152 * * \\
(.024)\end{array}$ & $\begin{array}{l}.147^{* *} \\
(.025)\end{array}$ & $\begin{array}{l}.149 * * \\
(.026)\end{array}$ & $\begin{array}{l}.145^{* *} \\
(.026)\end{array}$ & $\begin{array}{l}.175^{* *} \\
(.027)\end{array}$ & $\begin{array}{l}.192 * * \\
(.028)\end{array}$ & $\begin{array}{l}.195 * * \\
(.031)\end{array}$ \\
\hline $\begin{array}{l}\text { Real estate } \\
\text { knowledge }\end{array}$ & $\begin{array}{l}.026 \\
(.025)\end{array}$ & $\begin{array}{l}.046 \\
(.027)\end{array}$ & $\begin{array}{l}.020 \\
(.028)\end{array}$ & $\begin{array}{c}.024 \\
(.029)\end{array}$ & $\begin{array}{l}-.006 \\
(.028)\end{array}$ & $\begin{array}{c}.004 \\
(.030)\end{array}$ & $\begin{array}{l}.030 \\
(.031)\end{array}$ & $\begin{array}{l}-.008 \\
(.034)\end{array}$ \\
\hline $\begin{array}{l}\text { Susceptibility to } \\
\text { informational } \\
\text { influence }\end{array}$ & $\begin{array}{l}.099 * * \\
(.024)\end{array}$ & $\begin{array}{l}.070 * * \\
(.025)\end{array}$ & $\begin{array}{l}.078^{* *} \\
(.026)\end{array}$ & $\begin{array}{l}.090 * * \\
(.027)\end{array}$ & $\begin{array}{l}.102 * * \\
(.027)\end{array}$ & $\begin{array}{l}.137 * * \\
(.028)\end{array}$ & $\begin{array}{l}.131^{* *} \\
(.029)\end{array}$ & $\begin{array}{l}.131 * * \\
(.032)\end{array}$ \\
\hline $\begin{array}{l}\text { Susceptibility to } \\
\text { normative } \\
\text { influence }\end{array}$ & $\begin{array}{l}-.020 \\
(.027)\end{array}$ & $\begin{array}{c}.025 \\
(.028)\end{array}$ & $\begin{array}{c}.032 \\
(.029)\end{array}$ & $\begin{array}{c}.021 \\
(.030)\end{array}$ & $\begin{array}{c}.039 \\
(.030)\end{array}$ & $\begin{array}{c}.027 \\
(.031)\end{array}$ & $\begin{array}{c}.029 \\
(.032)\end{array}$ & $\begin{array}{l}-.004 \\
(.036)\end{array}$ \\
\hline Moral viewpoint & $\begin{array}{c}-.085^{* *} \\
(.019)\end{array}$ & $\begin{array}{c}-.096^{* *} \\
(.020)\end{array}$ & $\begin{array}{c}-.102 * * \\
(.020)\end{array}$ & $\begin{array}{c}-.103 * * \\
(.021)\end{array}$ & $\begin{array}{c}-.076^{* *} \\
(.021)\end{array}$ & $\begin{array}{c}-.056^{* *} \\
(.022)\end{array}$ & $\begin{array}{l}-.011 \\
(.022)\end{array}$ & $\begin{array}{c}.017 \\
(.025)\end{array}$ \\
\hline F-statistic & $12.471 * *$ & $14.68^{* *}$ & $14.09^{* *}$ & $13.77 * *$ & $13.11 * *$ & $15.54 * *$ & $14.99^{* *}$ & $11.77 * *$ \\
\hline$p$-value & .000 & .000 & .000 & .000 & .000 & .000 & .000 & .000 \\
\hline $\mathrm{R}^{2}$ & .103 & .119 & .114 & .112 & .107 & .125 & .121 & .097 \\
\hline
\end{tabular}

* Significant at $.05 ; * *$ Significant at .01

Note 1: Numbers in parentheses are standard errors

Note 2: Demographic variables are not reported due to their general lack of theoretical justification and significance

This table summarizes the regression output from a series of estimations attempting to explain the first measure of mimetic herding (the difference in likelihood of strategic default between Phases 1 and 2 of the experiment). Skewing Order refers to the scenario averages experimenters inserted in an attempt to herd participant scores either higher or lower. Presentation Order refers to whether Phase 1 of the experiment referred to the actions the participant would do if she were in the situation versus what they would recommend their friend would do. Signal Strength refers to the situation where the distribution of past participant responses was falsely reported to be extremely tightly centered about the mean (Leptokurtotic) in both phase, 0 otherwise. Maven Influencer is a dummy variable equal to 1 if an expert opinion was seen by the participant, 0 otherwise. Participant Influencer is a dummy variable equal to 1 if an expert opinion was seen by the participant, 0 otherwise. Can Be Easily Influenced reports how easily the participant thinks his answers can be influenced by others from 1 (not easily influenced) to 9 (easily influenced). Real Estate Knowledge reports the self-assessed level of knowledge from 1 (not knowledgeable) to 9 (very knowledgeable). Susceptibility to Informational Influence captures the self-assessed level of malleability due to information gains from 1 (not malleable) to 9 (very malleable). Susceptibility to Normative Influence captures the self-assessed level of malleability due to the social need to fit in from 1 (not malleable) to 9 (very malleable). Moral Viewpoint reflects the degree to which the participant believes it is morally wrong to strategically default on ones mortgage from 1 (not wrong) to 9 (very wrong) 
Table 5 Regressions to explain mimetic herding scores based on control group and fabricated means

\begin{tabular}{|c|c|c|}
\hline & Control group means & Fabricated group means \\
\hline Presentation order & $\begin{array}{l}-58.306^{* *} \\
(18.289)\end{array}$ & $\begin{array}{l}54.559^{*} \\
(24.215)\end{array}$ \\
\hline Signal strength & $\begin{array}{l}-29.318 \\
(18.516)\end{array}$ & $\begin{array}{l}4.878 \\
(24.517)\end{array}$ \\
\hline Maven influencer & $\begin{array}{l}99.383 * * \\
(23.919)\end{array}$ & $\begin{array}{l}-24.151 \\
(31.670)\end{array}$ \\
\hline Participant influencer & $\begin{array}{l}-4.010 \\
(26.034)\end{array}$ & $\begin{array}{l}25.006 \\
(34.470)\end{array}$ \\
\hline Can be easily influenced & $\begin{array}{l}9.075^{*} \\
(4.365)\end{array}$ & $\begin{array}{l}-54.954 * * \\
(5.779)\end{array}$ \\
\hline Real estate knowledge & $\begin{array}{l}3.908 \\
(4.732)\end{array}$ & $\begin{array}{l}-11.048 \\
(6.265)\end{array}$ \\
\hline Susceptibility to informational influence & $\begin{array}{l}6.583 \\
(4.587)\end{array}$ & $\begin{array}{l}-21.226^{* *} \\
(6.073)\end{array}$ \\
\hline Susceptibility to normative influence & $\begin{array}{l}-0.102 \\
(4.999)\end{array}$ & $\begin{array}{l}9.057 \\
(6.618)\end{array}$ \\
\hline Moral viewpoint & $\begin{array}{l}-14.411^{*} \\
(3.628)\end{array}$ & $\begin{array}{l}38.227 * * \\
(4.804)\end{array}$ \\
\hline F-statistic & $6.78 * *$ & $26.70 * *$ \\
\hline$p$-value & .000 & .000 \\
\hline $\mathrm{R}^{2}$ & .104 & .313 \\
\hline
\end{tabular}

* Significant at $.05 ; * *$ Significant at .01

Note 1: Numbers in parentheses are standard errors

Note 2: Demographic variables are not reported due to their general lack of theoretical justification and significance

This table summarizes the regression output from a series of estimations attempting to explain mimetic herding (the progressive movement towards increasing likelihood of strategically defaulting when the participant's house moves further and further underwater). Presentation Order refers to whether Phase 1 of the experiment referred to the actions the participant would do if she were in the situation versus what they would recommend their friend would do. Signal Strength refers to the situation where the distribution of past participant responses was falsely reported to be extremely tightly centered about the mean (Leptokurtotic) in both phase, 0 otherwise. Maven Influencer is a dummy variable equal to 1 if an expert opinion was seen by the participant, 0 otherwise. Participant Influencer is a dummy variable equal to 1 if an expert opinion was seen by the participant, 0 otherwise. Can Be Easily Influenced reports how easily the participant thinks his answers can be influenced by others from 1 (not easily influenced) to 9 (easily influenced). Real Estate Knowledge reports the self-assessed level of knowledge from 1 (not knowledgeable) to 9 (very knowledgeable). Susceptibility to Informational Influence captures the self-assessed level of malleability due to information gains from 1 (not malleable) to 9 (very malleable). Susceptibility to Normative Influence captures the self-assessed level of malleability due to the social need to fit in from 1 (not malleable) to 9 (very malleable). Moral Viewpoint reflects the degree to which the participant believes it is morally wrong to strategically default on ones mortgage from 1 (not wrong) to 9 (very wrong) 
participant moves farther from the control sample means (Eq. 2) or when the participant moves closer to the fabricated means (Eq. 3). Two sets of means are considered in this table. The first set of means to which participant scores are compared is the means observed within the control sample where nothing was done to influence participant responses. The justification for considering these is that this is a reasonable approximation for what the participants would have indicated in the absence of our experimental influences. The second set of means we use in the calculation of mimetic herding is the fabricated means artificially introduced by the authors. It makes sense to use these from the standpoint that the participants are led to believe that these are the responses from past participants.

To examine accumulated mimetic herding behavior, we consider the combination of experimental controls where the participant saw the high means in Phase I. The reason for this focus is because, based on the scores reported in the control group samples, we know that this experimental variant is the one where participants were confronted with reported group means that were most incongruent with their a priori answers. Alternatively stated, participants who began the experiment with high mean feedback in Phase 1 had to decide right away if they were going to retain their internal likelihood of strategically defaulting under each scenario or herd by following the (falsely) reported means.

The first column of Table 5 presents the results associated with the control sample mean comparisons. ${ }^{24}$ The observation of Maven behavior again significantly increases the herding activity of the sample, while signal strength does not. Participants who indicate they can be influenced by others are correct. Finally, those with a strong moral belief that it is wrong to strategically default are statistically significantly less likely to follow the (perceived) herd.

The second column of Table 5 again employs the Healy (2009) based measure, but this time uses the fabricated group means as the relevant benchmark instead of the control group means. We expect the signs of all variables to be reversed as we are now hypothesizing that participants will move towards the fabricated means (as opposed to away from their control group means), and this is exactly what happens. Upon first inspection, it seems surprising that the presence of a Maven becomes non-significant for the first time in the study. However, recall that the reported Maven score does not coincide with the fabricated means. Instead, it is intentionally reported as being on the extreme side of the mean (higher than the mean in "high mean" graphs and lower than the mean in "low mean" graphs). As such, we do not expect it to pull participants to the means. We expect Mavens to pull participants beyond the mean. As before, participants appear to herd for informational gains rather than for social reasons.

\footnotetext{
${ }^{24}$ Note that skewing order is necessarily absent from the list of explanatory variables as we restrict the sample to those who saw high mean graphs in the first phase. To be consistent with Table 4, we leave presentation order in the regression, but observe that its inclusion leaves qualitatively unchanged the coefficients and significance levels of all remaining variables within the model.
} 


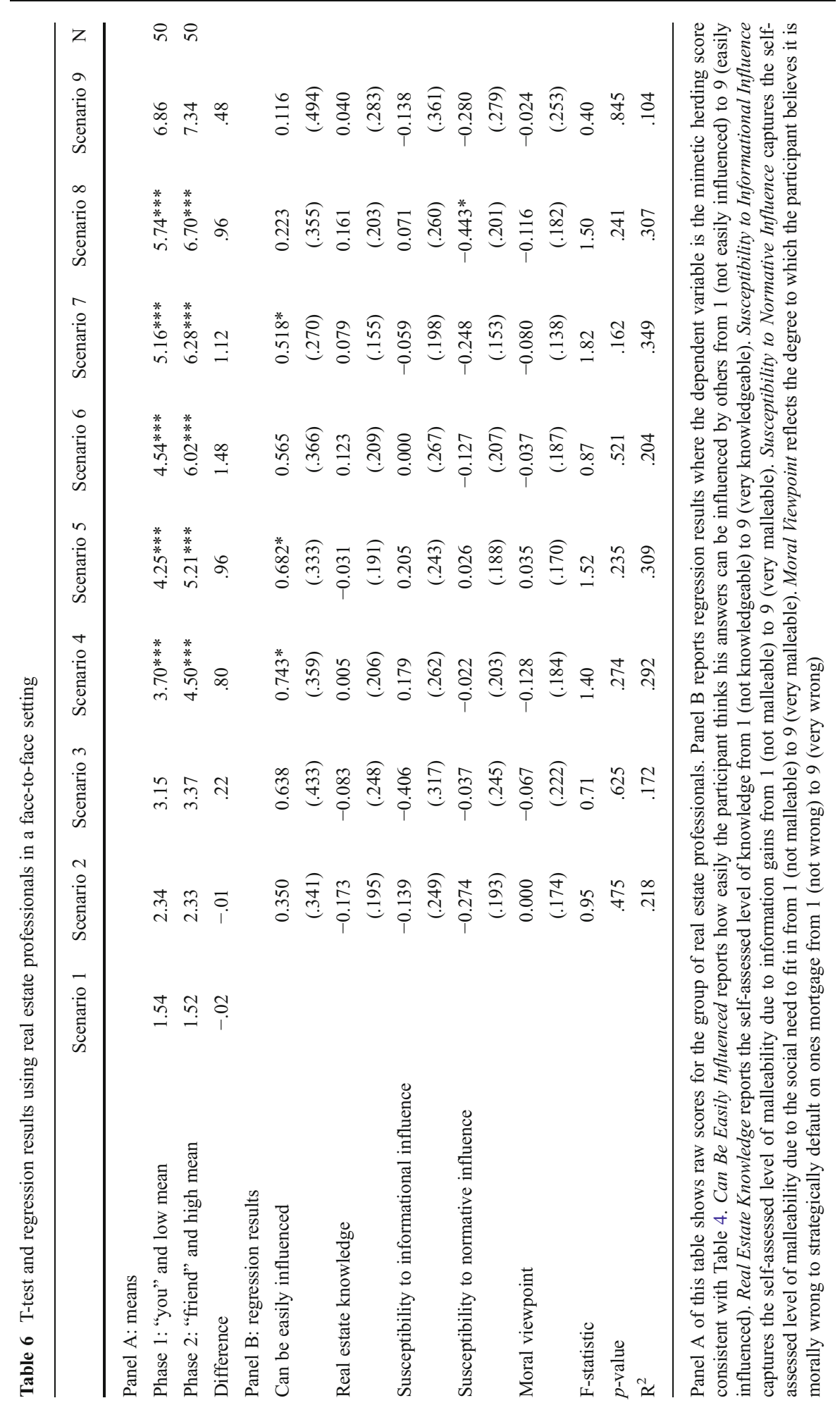




\section{Robustness Check}

Experimental settings are necessary to create an environment where all else is held constant and where a sufficient number of variants (50 in this study) can be carried out (Alevy et al. 2007). However, a question that often arises in an experimental study is whether or not the results would apply to a group of professionals (Harrison and List 2004; Locke and Mann 2005; Bikhchandani and Sharma 2000). For this reason, we conduct a variant of this study in a face-to-face setting using real estate professionals who are also homeowners. This is accomplished through the use of an Instant Response Device (IRD). An IRD is a credit card sized, hand-held electronic device that allows participants to register their responses to scenarios we construct on an interactive, real-time basis. Since participants are all located in the same room, we are able to test whether or not their responses are being influenced by the collective responses of their peers.

As with the Internet sample, we create the exact same (falsified) graphs that reflect both the mean and full distribution of participant responses. Since it is not possible to replicate all 50 variants of the study at once, we selected the variant where the professionals' Phase I (Phase II) graphs reflected low (high) means, a tight (tight) distribution, they were asked to describe their (friend) likelihood of strategic default, and with no external influencer. The results are shown in Table 6.

Panel A of Table 6 reports the means associated with the scenarios in each phase. Note that the Scenario 1 scores are almost identical indicating no difference between the advice the real estate professional would provide to a friend and what he would do for himself. Interestingly, significant differences do not occur until Scenario 4. This implies that it took three scenarios for participants to herd towards the values (they believe to be) reported by their peers. ${ }^{25}$ Scores stayed higher through Phase II, as hypothesized, based on the higher reported means shown to the audience.

In Panel B, regressions are estimated for each of the eight scenarios consistent with the process carried out in Table 4. The main difference is that the experimental design controls are necessarily absent, again due to the fact that only a single variant of this study (not all 50) was administered. These remaining independent variables do little to explain which particular participant attributes contribute to the herding behavior. In sum, it is clear that even professional real estate experts follow the herd in this context.

\section{Conclusions}

This study examines mimetic herding in an experimental setting to measure whether or not it is possible to change homeowners' stated willingness to strategically default at varying levels of negative equity. By falsely reporting the mean willingness to

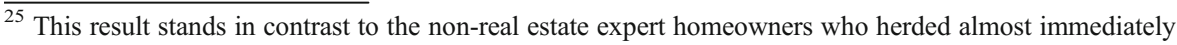
(in scenario 2 or 3 ).
} 
strategically default of their peers, participants significantly deviated from their prior positions. This behavioral departure is intensified when the homeowner (falsely) observes a Maven's, or market leader's choice in each scenario. When incorporating the participant's moral viewpoint on strategic default, homeowners are less likely to herd when they hold an a priori moral objection. Mimetic herding tests did not support malleability in a priori positions on the part of homeowners simply by reporting a difference in signal strength. Finally, based on the Bearden et al. (1989) measure of SII and SNI, homeowner participants appear to herd more for informational gains rather than for social purposes.

Motivated by Bikhchandani and Sharma (2000), we then performed a robustness check on the data by collecting a (second) sample of real estate industry professionals who are also homeowners. Consistent with theoretical expectations, even real estate professionals significantly herd after observing the behavior of their peers. Due to the difficulty of convening large groups of industry professionals, we leave further confirmatory variants of our experimental design to future research efforts.

Acknowledgments We would like to thank the Institute for Behavioral and Experimental Real Estate (IBERE) at Old Dominion University for providing funding for this study. We would also like to thank David Geltner, Markus Harder, an anonymous referee, and participants at the 2011 Maastricht-MIT-NUS (MNM) Real Estate Finance and Investments Symposium for their detailed comments and helpful feedback on earlier drafts. Finally, we thank Turning Technologies in Youngstown, OH, for loaning us the Instant Response Devices (IRDs) and software used to collect our live sample. All errors and omissions remain our own.

\section{Appendix}

Exhibit 1. Experimental Design Used to Conduct the Herding Experiment

In an effort to better understand the impact of the recent financial crisis, we are conducting a study of the residential real estate market. All responses will remain anonymous, so please answer openly and honestly to the following questions. There are no "right" or "wrong" answers.

Part A: Imagine yourself in each of the following hypothetical scenarios as they relate to YOUR primary residence (the home you own and live in).

Assume the following:

1. You have a fixed rate loan and can afford to continue making your mortgage payment.

2. You bought the home 4 years ago.

3. You do not expect home prices to go up or down at all over the next 3 years.

Please indicate the likelihood of you Strategically Defaulting (making the conscious decision to stop paying your mortgage even though you can afford to keep paying it) on the mortgage associated with YOUR primary 
residence (the home you own and live in) under the following home price decline scenarios.

\begin{tabular}{|c|c|c|c|c|c|c|c|c|c|c|c|c|c|c|}
\hline \multirow{3}{*}{ Scenario } & \multirow{3}{*}{$\begin{array}{c}\begin{array}{l}\text { Price you paid } \\
\text { for your home } \\
\text { four years ago }\end{array} \\
\$ 300,000\end{array}$} & \multirow{3}{*}{$\begin{array}{c}\begin{array}{c}\text { Down } \\
\text { Payment }\end{array} \\
\$ 30,000\end{array}$} & \multirow{3}{*}{$\begin{array}{c}\text { Outstanding } \\
\text { loan balance } \\
\text { today (amount } \\
\text { you still owe) }\end{array}$} & \multirow{3}{*}{$\begin{array}{c}\begin{array}{c}\text { Current } \\
\text { Price of } \\
\text { the home }\end{array} \\
\$ 240,000\end{array}$} & \multirow{3}{*}{$\begin{array}{c}\begin{array}{c}\text { Current } \\
\text { equity in } \\
\text { the home }\end{array} \\
-\$ 20,000\end{array}$} & \multicolumn{9}{|c|}{$\begin{array}{c}\text { Likelihood of you Strategically Defaulting } \\
\text { on your mortgage today }\end{array}$} \\
\hline & & & & & & \multicolumn{3}{|c|}{$\begin{array}{c}\text { Definitely } \\
\text { will NOT } \\
\text { choose to } \\
\text { default }\end{array}$} & \multirow[b]{2}{*}{4} & \multirow[b]{2}{*}{5} & & \multicolumn{3}{|c|}{$\begin{array}{c}\text { Definitely } \\
\text { will choose } \\
\text { to default }\end{array}$} \\
\hline & & & & & & 1 & 2 & 3 & & & 6 & 7 & E & 9 \\
\hline 2 & $\$ 300,000$ & $\$ 30,000$ & $\$ 260,000$ & $\$ 220,000$ & $-\$ 40,000$ & 1 & 2 & 3 & 4 & 5 & 6 & 7 & $\bar{\varepsilon}$ & 9 \\
\hline 3 & $\$ 300,000$ & $\$ 30,000$ & $\$ 260,000$ & $\$ 200,000$ & $-\$ 60,000$ & 1 & 2 & 3 & 4 & 5 & 6 & 7 & $\bar{\varepsilon}$ & 9 \\
\hline 4 & $\$ 300$ & $\$ 30,000$ & $\$ 26$ & $\$ 180$ & $-\$ 80,000$ & 1 & 2 & 3 & 4 & 5 & 6 & 7 & $\varepsilon$ & 9 \\
\hline 5 & $\$ 300,000$ & $\$ 30,000$ & $\$ 260,000$ & $\$ 160,000$ & $-\$ 100,000$ & 1 & 2 & 3 & 4 & 5 & 6 & 7 & & 9 \\
\hline 6 & $\$ 300,000$ & $\$ 30,000$ & $\$ 260,000$ & $\$ 140,000$ & $-\$ 120,000$ & 1 & 2 & 3 & 4 & 5 & 6 & 7 & & 9 \\
\hline 7 & $\$ 300,000$ & $\$ 30,000$ & $\$ 260,000$ & $\$ 120,000$ & $-\$ 140,000$ & 1 & 2 & 3 & 4 & 5 & 6 & 7 & $\bar{\varepsilon}$ & 9 \\
\hline 8 & $\$ 300,000$ & $\$ 30,000$ & $\$ 260,000$ & $\$ 100,000$ & $-\$ 160,000$ & 1 & 2 & 3 & 4 & 5 & 6 & 7 & z & 9 \\
\hline 9 & $\$ 300,000$ & $\$ 30,000$ & $\$ 260,000$ & $\$ 0$ & $-\$ 260,000$ & 1 & 2 & 3 & 4 & 5 & 6 & 7 & & 9 \\
\hline
\end{tabular}

Part B: Now imagine a friend of yours has come to you for advice on what to do in each of the following scenarios as it relates to his primary residence. Remember, all responses are anonymous, so please answer openly and honestly to the following questions. There are no "right" or "wrong" answers.

Assume the following:

1. He has a fixed rate loan and can afford to continue making his mortgage payment.

2. He bought the home 4 years ago.

3. He does not expect home prices to go up or down at all over the next 3 years.

Please indicate the likelihood of you recommending to your friend that he Strategically Default (making the conscious decision to stop paying his mortgage even though he can afford to keep paying it) on the mortgage associated with HIS primary residence (the home he owns and lives in) under the following home price decline scenarios.

\begin{tabular}{|c|c|c|c|c|c|c|c|c|c|c|c|c|c|}
\hline \multirow[b]{2}{*}{ Scenario } & \multirow{2}{*}{$\begin{array}{l}\text { Price you paid } \\
\text { for your home } \\
\text { four years ago }\end{array}$} & \multirow[b]{2}{*}{$\begin{array}{c}\text { Down } \\
\text { Payment }\end{array}$} & \multirow[b]{2}{*}{$\begin{array}{l}\text { Outstanding } \\
\text { loan balance } \\
\text { today (amount } \\
\text { you still owe) }\end{array}$} & \multirow[b]{2}{*}{$\begin{array}{c}\text { Current } \\
\text { Price of } \\
\text { the home }\end{array}$} & \multirow[b]{2}{*}{$\begin{array}{c}\text { Current } \\
\text { equity in } \\
\text { the home }\end{array}$} & \multicolumn{8}{|c|}{$\begin{array}{c}\text { Likelihood of you recommending } \\
\text { Strategically Default on } \\
\text { his mortgage today }\end{array}$} \\
\hline & & & & & & $\begin{array}{r}\text { Def } \\
\text { wil } \\
\text { cho } \\
\text { de }\end{array}$ & $\begin{array}{l}\text { initel } \\
\text { NO } \\
\text { ose } \\
\text { fault }\end{array}$ & & & & & & $\begin{array}{l}\text { Definitely } \\
\text { will choose } \\
\text { to default }\end{array}$ \\
\hline 1 & $\$ 300,000$ & $\$ 30,000$ & $\$ 260,000$ & $\$ 240,000$ & $-\$ 20,000$ & 1 & 2 & 3 & 4 & 5 & 6 & 7 & 89 \\
\hline 2 & $\$ 300,000$ & $\$ 30,000$ & $\$ 260,000$ & $\$ 220,000$ & $-\$ 40,000$ & 1 & 2 & 3 & 4 & 5 & 6 & 7 & 89 \\
\hline 3 & $\$ 300,000$ & $\$ 30,000$ & $\$ 260,000$ & $\$ 200,000$ & $-\$ 60,000$ & 1 & 2 & 3 & 4 & 5 & 6 & 7 & 89 \\
\hline 4 & $\$ 300,000$ & $\$ 30,000$ & $\$ 260,000$ & $\$ 180,000$ & $-\$ 80,000$ & 1 & 2 & 3 & 4 & 5 & 6 & 7 & 89 \\
\hline 5 & $\$ 300,000$ & $\$ 30,000$ & $\$ 260,000$ & $\$ 160,000$ & $-\$ 100,000$ & 1 & 2 & 3 & 4 & 5 & 6 & 7 & 89 \\
\hline 6 & $\$ 300,000$ & $\$ 30,000$ & $\$ 260,000$ & $\$ 140,000$ & $-\$ 120,000$ & 1 & 2 & 3 & 4 & 5 & 6 & 7 & 89 \\
\hline 7 & $\$ 300,000$ & $\$ 30,000$ & $\$ 260,000$ & $\$ 120,000$ & $-\$ 140,000$ & 1 & 2 & 3 & 4 & 5 & 6 & 7 & 89 \\
\hline 8 & $\$ 300,000$ & $\$ 30,000$ & $\$ 260,000$ & $\$ 100,000$ & $-\$ 160,000$ & 1 & 2 & 3 & 4 & 5 & 6 & 7 & 89 \\
\hline 9 & $\$ 300,000$ & $\$ 30,000$ & $\$ 260,000$ & $\$ 0$ & $-\$ 260,000$ & 1 & 2 & 3 & 4 & 5 & 6 & 7 & 89 \\
\hline
\end{tabular}


Part C:

Please answer number 3 for this question.

5

\begin{tabular}{ccccccc}
6 & 7 & \multicolumn{2}{c}{8} & \multicolumn{2}{c}{9} \\
\multicolumn{2}{c}{$\begin{array}{c}\text { Strongly } \\
\text { Disagree } \\
1\end{array}$} & & & Neutral & \multicolumn{3}{c}{$\begin{array}{c}\text { Strongly } \\
\text { Agree }\end{array}$} \\
1 & 2 & 3 & 4 & 5 & 6 & 7 \\
1 & 2 & 3 & 4 & 5 & 6 & 7 \\
1 & 2 & 3 & 4 & 5 & 6 & 7 \\
1 & 2 & 3 & 4 & 5 & 6 & 7 \\
1 & 2 & 3 & 4 & 5 & 6 & 7
\end{tabular}

My answers to the above scenarios can be easily influenced by others.

I am very knowledgeable about real estate.

I often consult other people before making an important real estate decision.

I like to know what real estate decisions make good impressions on others.

I know someone who has strategically defaulted on their mortgage.

It is morally wrong to strategically default on one's mortgage.

Please share the following demographic information about yourself:

Gender: Male Female

Number of children: children

Number of children below age 18: children

What is your Age?

Please answer number 8 for this question.
1
3
4
5
$\begin{array}{lll}6 & 7 & 8\end{array}$
9

Current Marital Status: Single Married Divorced Widowed

Ethnicity:

African American

Caucasian

Other

Highest Education Attained

(Please check the appropriate box)

Ph.D.

Master's Degree

Bachelor's Degree

Some college

High School Diploma

Less than High School Diploma
_ Asian

- Hispanic

Your Annual Income Level

(Please check the appropriate box)

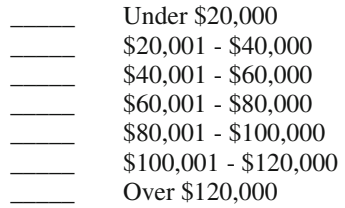

What is your total Net Worth? Net Worth is defined as total assets (stocks, bonds, price of your home, retirement accounts, etc.) minus total liabilities (outstanding mortgage balance, credit card debt, student loans, auto loans, etc.)

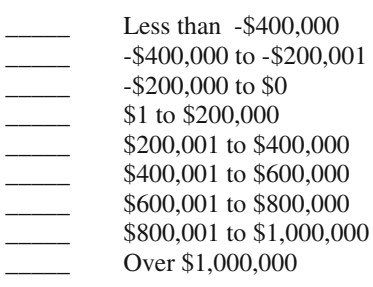


Exhibit 2. Screen Capture of Slide Showing the Fabricated Outcome of Results Associated with Scenario 4 for a Tight Graph with High Means

\section{Scenario 4}

\begin{tabular}{|c|c|c|c|c|c|c|c|c|c|c|c|c|c|c|}
\hline \multirow{3}{*}{$\begin{array}{c}\text { Scenario } \\
1\end{array}$} & \multirow{3}{*}{$\begin{array}{c}\begin{array}{c}\text { Price you } \\
\text { paid for your } \\
\text { home } \\
\text { four years } \\
\text { ago }\end{array} \\
\$ 300,000\end{array}$} & \multirow{3}{*}{$\begin{array}{c}\text { Down } \\
\text { Payment } \\
\$ 30,000\end{array}$} & \multirow{3}{*}{$\begin{array}{c}\text { Outstanding } \\
\text { loan balance } \\
\text { today (amount } \\
\text { you still owe) }\end{array}$} & \multirow{3}{*}{$\begin{array}{l}\text { Current } \\
\text { Price of } \\
\text { the home }\end{array}$} & \multirow{3}{*}{$\begin{array}{c}\begin{array}{c}\text { Current } \\
\text { equity in } \\
\text { the home }\end{array} \\
-\$ 20,000 \\
\end{array}$} & \multicolumn{9}{|c|}{$\begin{array}{l}\text { Likelihood of you recommending } \\
\text { Strategically Default on } \\
\text { his mortgage today }\end{array}$} \\
\hline & & & & & & \multicolumn{2}{|c|}{$\begin{array}{l}\text { Definitely } \\
\text { will NOT } \\
\text { choose to } \\
\text { default }\end{array}$} & & \multirow[b]{2}{*}{4} & \multirow[b]{2}{*}{5} & \multirow[b]{2}{*}{6} & \multicolumn{3}{|c|}{$\begin{array}{l}\text { Definitely } \\
\text { will choose } \\
\text { to default }\end{array}$} \\
\hline & & & & & & 1 & 2 & 3 & & & & 7 & 8 & 9 \\
\hline 2 & $\$ 300,000$ & $\$ 30,000$ & $\$ 260,000$ & $\$ 220,000$ & $-\$ 40,000$ & 1 & 2 & 3 & 4 & 5 & 6 & 7 & 8 & 9 \\
\hline 3 & $\$ 300,000$ & $\$ 30,000$ & $\$ 260,000$ & $\$ 200,000$ & $-\$ 60,000$ & 1 & 2 & 3 & 4 & 5 & 6 & 7 & 8 & 9 \\
\hline 4 & $\$ 300,000$ & $\$ 30,000$ & $\$ 260,000$ & $\$ 180,000$ & $-\$ 80,000$ & 1 & 2 & 3 & 4 & 5 & 6 & 7 & 0 & 9 \\
\hline 5 & $\$ 300,000$ & $\$ 30,000$ & $\$ 260,000$ & $\$ 160,000$ & $-\$ 100,000$ & 1 & 2 & 3 & 4 & 5 & 6 & 7 & 8 & 9 \\
\hline 6 & $\$ 300,000$ & $\$ 30,000$ & $\$ 260,000$ & $\$ 140,000$ & $-\$ 120,000$ & 1 & 2 & 3 & 4 & 5 & 6 & 7 & 8 & 9 \\
\hline 7 & $\$ 300,000$ & $\$ 30,000$ & $\$ 260,000$ & $\$ 120,000$ & $-\$ 140,000$ & 1 & 2 & 3 & 4 & 5 & 6 & 7 & o & 9 \\
\hline 8 & $\$ 300,000$ & $\$ 30,000$ & $\$ 260,000$ & $\$ 100,000$ & $-\$ 160,000$ & 1 & 2 & 3 & 4 & 5 & 6 & 7 & 8 & 9 \\
\hline 9 & $\$ 300,000$ & $\$ 30,000$ & $\$ 260,000$ & $\$ 0$ & $-\$ 260,000$ & 1 & 2 & 3 & 4 & 5 & 6 & 7 & 8 & 9 \\
\hline
\end{tabular}

\section{Definitely will NOT default}

\section{Definitely WILL default}

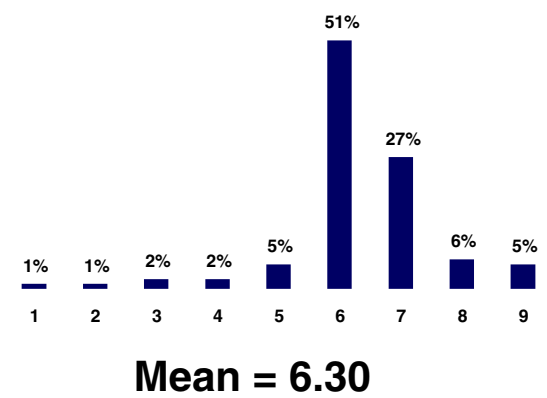

Exhibit 3. Illustration of the Four Distinct Distribution Shapes (signal strengths) Used Throughout the Study for Scenario 4

Panel A: Low and Tight

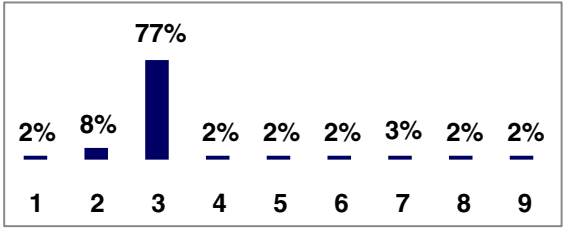

Panel B: Low and Wide

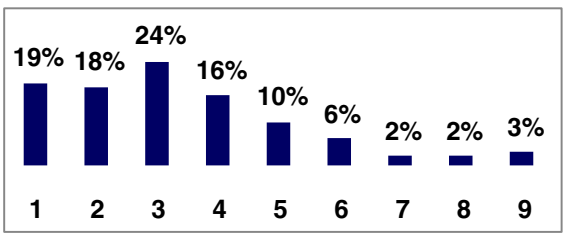

Panel C: High and Tight

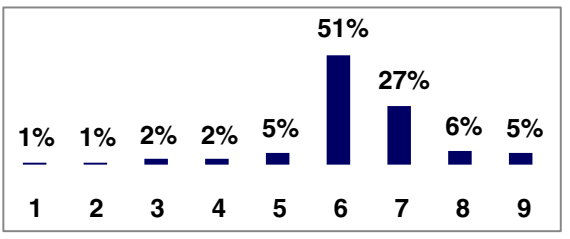

Panel D: High and Wide

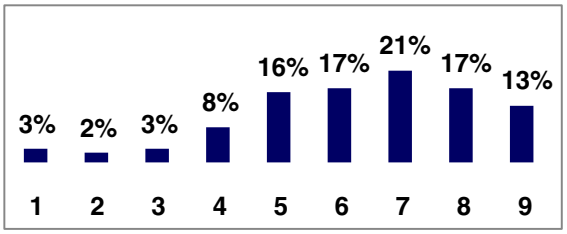


Exhibit 4. Participant and Maven Influencer Names and Affiliations

This exhibit shows the fictitious names used for both the past participants and real estate experts (Mavens). Names were randomly paired across the 18 scenarios. For the Maven trials, newspaper names we added as well. For the past participant trials, City and State affiliations were randomly selected from a population-weighted draw without replacement.

\begin{tabular}{lll}
\hline Newspapers & First Names & Last Names \\
USA Today & Male & Miller \\
Wall Street Journal & Sam & Ritner \\
New York Times & Robert & Clark \\
Los Angeles Times & Kyle & King \\
Washington Post & Elliot & Green \\
Chicago Tribune & Matt & Baker \\
Philadelphia Inquirer & David & Morris \\
Rocky Mountain News (Denver) & Paul & Bailey \\
Houston Chronicle & Richard & Watson \\
& George & Griffin \\
San Francisco Chronicle & Female & Myers \\
Dallas Morning News & Jessica & Crawford \\
Detroit Free Press & Sarah & Dixon \\
Star Tribune (Minneapolis) & Linda & Reese \\
Boston Globe & Sandra & Somner \\
Plain Dealer (Cleveland) & Laura & Yager \\
Miami Herald & Janet & Daltry \\
Kansas City Star & Debra & Nash \\
Charlotte Observer & Stephanie & Amanda \\
\hline
\end{tabular}

Exhibit 5. Flowchart Showing a Breakdown of the Experimental Design used in the Study

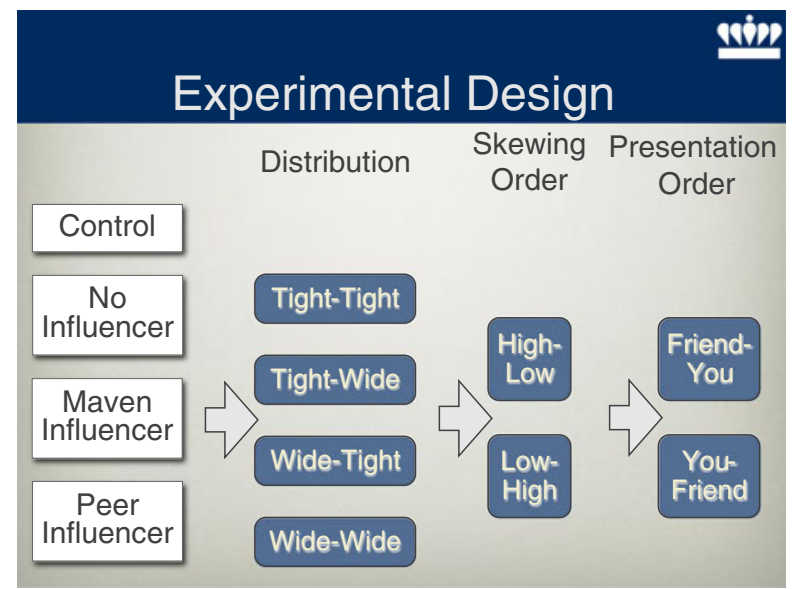


Exhibit 6. Mimetic Herding Scores-Eq. 2

This graph shows average mimetic herding scores for the main sample based on the deviation from the control group's score for each question. The upward trend means the participant's indication of willingness to default gets farther from the control group's answer as the questions proceed, providing evidence of mimetic herding.

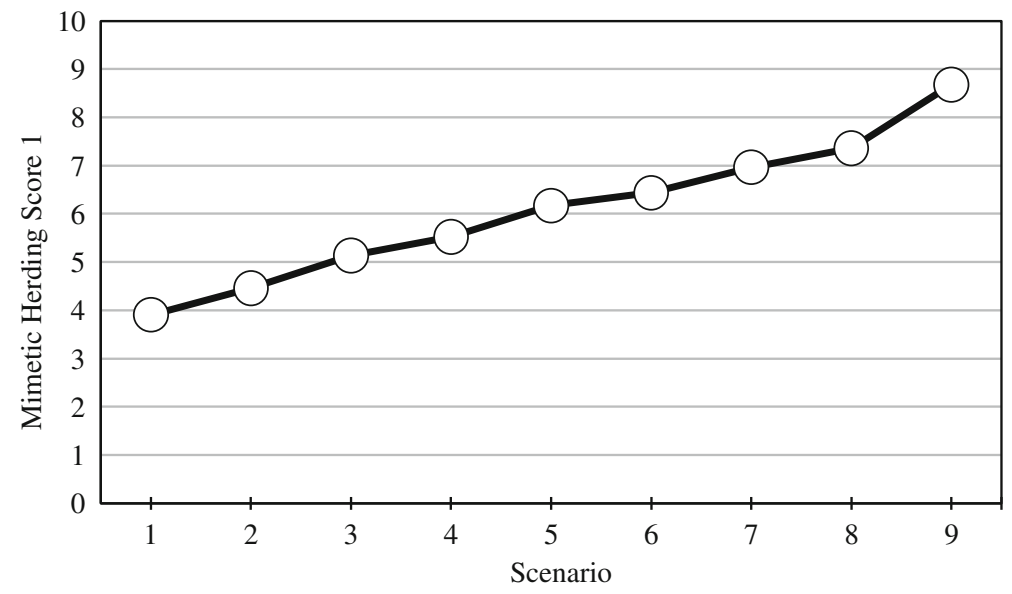

Exhibit 7. Mimetic Herding Scores-Eq. 3

This graph shows average mimetic herding scores for the main sample based on the deviation from the fabricated means for each question. The downward trend means the participant's indication of willingness to default gets closer to the fabricated means as the questions proceed, providing evidence of mimetic herding.

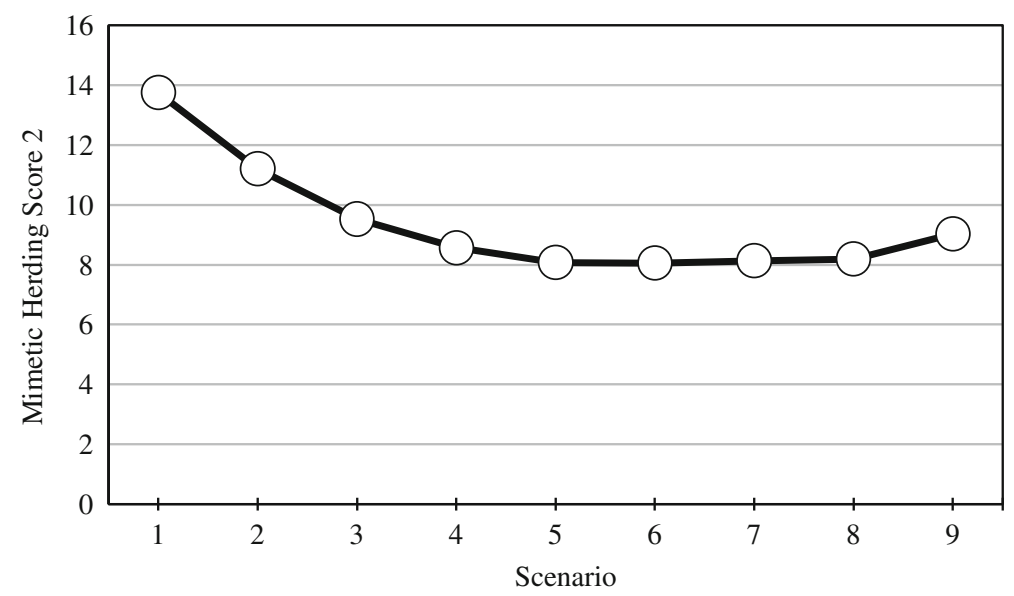




\section{References}

Alevy, J., Haigh, M., \& List, J. (2007). Information cascades: Evidence from a field experiment with financial market professionals. Journal of Finance, 62(1), 151-180.

Anderson, L., \& Holt, C. (1997). Information cascades in the laboratory. American Economic Review, 87 (5), 847-862.

Bearden, W. O., Netemeyer, R. G., \& Teel, J. E. (1989). Measurement of consumer susceptibility to interpersonal influence. Journal of Consumer Research, 15, 473-481.

Bikhchandani, S., \& Sharma, S. (2000). "Herd behavior in financial markets: A review”. IMF Working Paper 48 .

Bikhchandani, S., Hirshleifer, D., \& Welch, I. (1992). A theory of fads, fashion, custom, and cultural change as informational cascades. Journal of Political Economy, 100, 992-1026.

Bikhchandani, S., Hirshleifer, D., \& Welch, I. (1998). Learning from the behavior of others: Conformity, fads, and informational cascades. Journal of Economic Perspectives, 12, 151-170.

Celen, B., \& Kariv, S. (2004). Distinguishing informational cascades from herd behavior in the laboratory. American Economic Review, 94(3), 484-497.

Chamley, C. (2004). Rational herds: Economic models of social learning. New York: Cambridge University Press.

Chari, V., \& Kehoe, P. (2004). Financial crisis as herds: Overturning the critiques. Journal of Economic Theory, 119, 128-150.

Diamond, D., \& Dybvig, P. (1983). Bank runs, deposit insurance, and liquidity. Journal of Political Economy, 91, 401-409.

Eichengreen, B., Mathieson, D., Chadha, B., Jansen, A., Kodres, L., Sharma, S. (1998). "Hedge funds and financial market dynamics". IMF Occasional Paper No. 166.

Engelberg, J., \& Parsons, C. (2011). The causal impact of media in financial markets. Journal of Finance, $66(1), 67-97$.

Farnsworth, W. (2007). The legal analyst: A toolkit for thinking about the law. Chicago: University Press.

Feick, L. F., \& Price, L. L. (1987). The market maven: A diffuser of marketplace information. Journal of Marketing, 51, 83-97.

Fernández, B., Garcia-Merino, T., Mayoral, R., Santos, V., \& Vallelado, E. (2011). Herding, information uncertainty and investors' cognitive profile. Qualitative Research in Financial Markets, 3, 7-33.

FICO. (2011). "Predicting strategic default". April, white paper.

Fisher, R., \& Yates, F. (1938). Statistical tables for biological, agricultural and medical research (pp. 2627). London: Oliver \& Boyd.

Guiso, L., Sapienza, P., Zingales, L. (2011). "Moral and social constraints to strategic default on mortgages." Journal of Finance, forthcoming.

Harrison, G., \& List, J. (2004). Field experiments. Journal of Economic Literature, 42, 1009-1055.

Healy, A. (2009). How effectively do people learn from a variety of different opinions? Experimental Economics, 12, 386-416.

Hirshleifer, D., Subrahmanyam, A., \& Titman, S. (1994). Security analysis and trading patterns when some investors receive information before others. Journal of Finance, 49(5), 1665-1698.

Jegadeesh, N., \& Kim, W. (2010). Do analysts herd? an analysis of recommendations and market reactions. Review of Financial Studies, 23(2), 901-937.

Keynes, J. (1965). The general theory of employment, interest, and money. New York: Harcourt Brace \& World.

Knuth, D. (1969). The art of computer programming, volume 2: Seminumerical algorithms (pp. 124-125). Reading: Addison-Wesley.

Locke, P., \& Mann, S. (2005). Professional trader discipline and trade disposition. Journal of Financial Economics, 76, 401-444.

Marsden, P. (1998). Memetics and social contagion: Two sides of the same coin? Journal of Memetics, 2(2), 68-86.

Morris, S., \& Shin, H. (1999). Risk management with interdependent choice. Oxford Review of Economic Policy, 15(3), 52-62.

Persaud, A. (2000). "Sending the herd off the cliff edge: The disturbing interaction between herding and market-sensitive risk management practices." In Jacques de Larosiere essays on global finance. Institute of International Finance: Washington.

Rogers, E. (1962). Diffusion of innovation. New York: Free Press. 
Seiler, M. (2004). Performing financial studies: A methodological cookbook. Upper Saddle River: Prentice Hall.

Seiler, M., Seiler, V., Lane, M., Harrison, D. (2011). “An examination of the economic and behavioral motivations underlying the decision to strategically default." Real Estate Economics, forthcoming.

Shiller, R. (1990). "Investor behavior in the October 1987 stock market crash: Survey evidence". In Market volatility. MIT Press: Cambridge, Massachusetts.

Shiller, R. (2008). "How a bubble stayed under the radar”. http://www.nytimes.com/2008/03/02/business/ 02view.html.

Wheaton, W., \& Nechayev, G. (2011). “Rebalancing the US housing market: Two proposals, ” working paper, MIT.

White, B. (2010). Underwater and not walking away: Shame, fear, and the social management of the housing crisis. Wake Forest Law Review, 45, 971-1023.

Wyman, O. (2010). "Understanding strategic default in mortgages". Experian Report. 